\title{
Specific caspase interactions and amplification are involved in selective neuronal vulnerability in Huntington's disease
}

\author{
E Hermel $^{1,2}$, J Gafni ${ }^{1}$, SS Propp ${ }^{1}$, BR Leavitt ${ }^{3}$, CL Wellington ${ }^{3}$, \\ JE Young ${ }^{1}$, AS Hackam ${ }^{3}$, AV Logvinova ${ }^{1}$, AL Peel ${ }^{1}$, SF Chen ${ }^{1}$, \\ V Hook ${ }^{1}$, R Singaraja ${ }^{3}$, S Krajewski ${ }^{4}$, PC Goldsmith ${ }^{1}$, \\ HM Ellerby ${ }^{1}$, MR Hayden ${ }^{3}$, DE Bredesen ${ }^{1,4}$ and LM Ellerby ${ }^{*, 1}$ \\ 1 The Buck Institute for Age Research, Novato, CA, USA; \\ 2 Touro University College of Osteopathic Medicine, Vallejo, CA, USA; \\ ${ }^{3}$ Department of Pathology and Laboratory Medicine or Centre for Molecular \\ Medicine and Therapeutics, Department of Medical Genetics, University of \\ British Columbia, Vancouver, British Columbia, Canada; \\ ${ }^{4}$ Program on Aging and Apoptosis, The Burnham Institute, La Jolla, CA, USA \\ * Corresponding author: LM Ellerby, The Buck Institute for Age Research, 8001 \\ Redwood Blvd, Novato, CA 94945, USA. Tel: 415 -209 2088; \\ Fax: 415 -209 2230; E-mail: lellerby@ buckinstitute.org
}

Received 01.5.03; revised 16.10.03; accepted 27.10.03; published online 9.1.04 Edited by Dr P Nicotera

\begin{abstract}
Huntington's disease (HD) is an autosomal dominant progressive neurodegenerative disorder resulting in selective neuronal loss and dysfunction in the striatum and cortex. The molecular pathways leading to the selectivity of neuronal cell death in HD are poorly understood. Proteolytic processing of full-length mutant huntingtin (Htt) and subsequent events may play an important role in the selective neuronal cell death found in this disease. Despite the identification of $\mathrm{Htt}$ as a substrate for caspases, it is not known which caspase(s) cleaves Htt in vivo or whether regional expression of caspases contribute to selective neuronal cells loss. Here, we evaluate whether specific caspases are involved in cell death induced by mutant $\mathrm{Htt}$ and if this correlates with our recent finding that $\mathrm{Htt}$ is cleaved in vivo at the caspase consensus site 552 . We find that caspase-2 cleaves $\mathrm{Htt}$ selectively at amino acid 552. Further, $\mathrm{Htt}$ recruits caspase-2 into an apoptosome-like complex. Binding of caspase-2 to $\mathrm{Htt}$ is polyglutamine repeat-length dependent, and therefore may serve as a critical initiation step in HD cell death. This hypothesis is supported by the requirement of caspase-2 for the death of mouse primary striatal cells derived from HD transgenic mice expressing full-length Htt (YAC72). Expression of catalytically inactive (dominant-negative) forms of caspase-2, caspase-7, and to some extent caspase-6, reduced the cell death of YAC72 primary striatal cells, while the catalytically inactive forms of caspase $-3,-8$, and -9 did not. Histological analysis of post-mortem human brain tissue and YAC72 mice revealed activation of caspases and enhanced caspase-2 immunoreactivity in medium spiny neurons of the striatum and the cortical projection neurons when compared to controls. Further, upregulation of caspase-2 correlates
\end{abstract}

directly with decreased levels of brain-derived neurotrophic factor in the cortex and striatum of 3-month YAC72 transgenic mice and therefore suggests that these changes are early events in HD pathogenesis. These data support the involvement of caspase-2 in the selective neuronal cell death associated with $\mathrm{HD}$ in the striatum and cortex.

Cell Death and Differentiation (2004) 11, 424-438. doi:10.1038/ s..cdd. 4401358

Published online 9 January 2004

Keywords: Huntington's disease; caspase; apoptosis; polyglutamine

Abbreviations: HD, Huntington's disease; Htt, huntingtin; BDNF, brain-derived neurotrophic factor; GFP, green fluorescent protein; TUNEL, terminal deoxynucleotidyl transferase-mediated dUTP nick-end labeling; PVDF, polyvinylidene fluoride; GFAP, glial fibrillary acidic protein

\section{Introduction}

Expansion of CAG trinucleotide repeats that encode polyglutamine tracts in nine otherwise unrelated proteins is the common mutation underlying nine distinct neurodegenerative diseases. ${ }^{1-11}$ Expansion of polyglutamine repeats is associated with a toxic gain-of-function that affects specific neuronal populations in each of these diseases. ${ }^{12}$ Huntington's disease (HD), one of the most extensively studied of these diseases, is a debilitating inherited neurodegenerative disorder characterized by involuntary movements, personality changes, dementia, and early death. ${ }^{13} \mathrm{HD}$ is characterized by selective neuronal loss and fibrillary reactive astrocytosis predominantly within the striatum and cortex. ${ }^{14,15}$

The selectivity of neuronal death seen in HD striatum and cortex is remarkable given that huntingtin protein $(\mathrm{Htt})$ is normally expressed throughout the central nervous system as well as in non-neuronal cells. ${ }^{16-18} \mathrm{Htt}$ is also widely distributed at the subcellular level and has been found within nuclei, perikarya, neurites, and synaptic elements. ${ }^{16-21}$ Considering the widespread expression of $\mathrm{Htt}$, it is interesting that the enkephalin and substance P-containing medium spiny neurons are vulnerable in the striatum, while large cholinergic and medium aspiny neurons are spared. ${ }^{14,22-24}$ In the cortex, the pyramidal cortical projection neurons in layers III and V are vulnerable. Markers of apoptosis have been detected in the brains of patients with $\mathrm{HD}$ in both of these regions. ${ }^{25}$

Despite the numerous studies in vitro and in vivo supporting a correlation between $\mathrm{Htt}$ length and toxicity, little is known about how cleavage events may be initiated or how the proteolytic processing of $\mathrm{Htt}$ or other polyglutamine disease proteins is regulated. ${ }^{26-29}$ Cell-type-dependent cleavage by 
specific caspases or other proteases may explain some of the selective neurodegeneration seen in these diseases. Evidence for region-specific cleavage of $\mathrm{Htt}$ in vivo comes from studies of YAC transgenic mice expressing mutant full-length huntingtin (YAC72). In this model, $\mathrm{N}$-terminal fragments of $\mathrm{Htt}$ are clearly found in the medium spiny neurons of the striatum $^{30}$ and cortex, ${ }^{31}$ but not in other regions of the brain unaffected in HD. These results suggest that cleavage of $\mathrm{Htt}$ by caspases and other proteases such as calpains ${ }^{32}$ may produce toxic fragments. However, it does not explain how cleavage is initiated, which caspases cleave Htt in vivo, nor how selective regional neuronal cell loss occurs in HD. We hypothesized that three factors might be involved in this process: (1) the cell-specific expression of proteases within the striatum and cortex that cleave $\mathrm{Htt}$ in vivo, (2) the ability of $\mathrm{Htt}$ to interact with cell-death signaling molecules and be cleaved in a region-specific manner, and (3) the regulation of these caspases by brain-derived neurotrophic factor (BDNF). BDNF levels are directed regulated by wild-type $\mathrm{Htt}$ and are reduced in HD transgenic mice and HD patient brains. ${ }^{33}$

We find that caspase- 2 cleaves $\mathrm{Htt}$ selectively at amino acid 552, which is the $\mathrm{Htt}$ caspase cleavage product detected in vivo both in early-grade HD postmortem tissue and in YAC transgenic mice expression mutant $\mathrm{Htt}^{31}$ and further that $\mathrm{Htt}$ directly interacts with specific caspases to form a cell-death complex. We found that caspase-2, -6 , and -7 recruit $\mathrm{Htt}$ in an apoptosome-like complex. Caspase- 2 and -7 bound full-length Htt while caspase- 6 bound the $\mathrm{N}$-terminal caspase cleavage product. Furthermore, the binding of initiator caspase-2 was repeat-length dependent, which could explain why the length of the polyglutamine tract correlates with the age of disease onset. Caspase- 2 was required for the death of primary striatal cells derived from YAC72 transgenic mice. Analysis of YAC72 transgenic mice ${ }^{30}$ and post-mortem brain from HD patients confirmed the contribution of caspase-2 to the pathogenesis of HD. Furthermore, caspase- 2 mRNA levels are regulated by trophic support from the growth factor, BDNF. The upregulation of caspase-2 correlates directly with decreased levels of BDNF in the cortex and striatum of 3-month YAC72 transgenic mice and therefore suggests that activation of these pathways maybe an early event in the pathogenesis of HD.

\section{Results}

\section{HD is specifically cleaved by caspase-2 at caspase consensus site 552 in vitro and in vivo}

The caspase cleavage sites of $\mathrm{Htt}$ are clustered around a 76 amino-acid region of $\mathrm{Htt}$ (Figure $1 \mathrm{a}$ ) and cleavage in this region generates $\mathrm{N}$-terminal fragments that have been shown to be toxic in cells. ${ }^{34-36}$ We have previously shown that $\mathrm{Htt}$ is cleaved in vitro by caspase-3 at amino acids 513 and 552, and by caspase- 6 at amino-acid position $586 .{ }^{36}$ However, in vivo, we found that $\mathrm{Htt}$ is specifically cleaved at a caspase consensus site at amino acid 552 in pyramidal cortical neurons, while the caspase consensus site at amino acid 513 does not appear to be utilized. ${ }^{31}$ Since caspase- 3 cleaves at both D513 and D552, we further evaluated the specificity of caspases in cleaving $\mathrm{Htt}$. Here, we show that $\mathrm{Htt}$ is also cleaved by caspase-2, -7 , and -8 (Figure $1 \mathrm{~b}$ ). Cleavage of $\mathrm{Htt}$

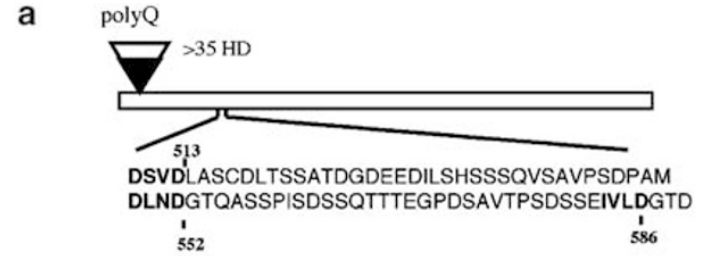

b
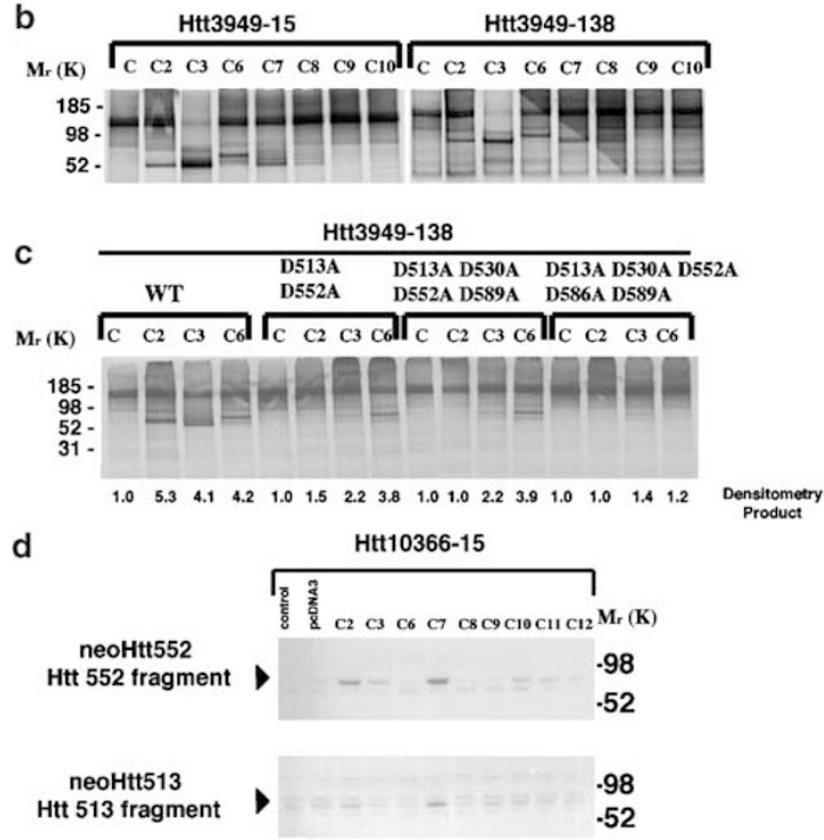

Figure 1 In vitro cleavage of $\mathrm{Htt}$ with recombinant caspases. (a) Htt caspase cleavage sites are clustered around a 76 amino-acid region of $\mathrm{Htt}$. (b) Radiolabeled Htt with 15 (pRC-CMV3949-15; construct yielding the first 1212 amino acids of $\mathrm{Htt}$ ) and 138 glutamine repeats (pRC-CMV3949-138) were incubated with the indicated recombinant caspases $(\sim 10-100 \mathrm{nM})$ or in cleavage buffer (uncleaved). It should be noted that that $\mathrm{Htt}$ is cleaved by caspase-8 in vitro, although less efficiently. The recombinant caspase- 3 and -7 was purified via a different method with higher specific activity and therefore accounts for the difference reported in our previous work. ${ }^{29}$ (c) Radiolabeled caspase-resistant forms of $\mathrm{Htt}$ with 138 repeats (pRC-CMV3949-138) were incubated with the indicated recombinant caspases $(\sim 100 \mathrm{nM})$ or in cleavage buffer (uncleaved) in order to determine the site of caspase-2 cleavage. Densitometry of the caspase cleavage products of $\mathrm{Htt}$ indicate that caspase-2, -3 , -6 cleaved $\mathrm{Htt}$ with similar efficacy and the caspase-resistant forms are resistant to cleavage relative to control. (d) Western blot analysis of lysates from 293T cells transfected with the indicated $\mathrm{Htt}$ and caspase constructs ( $48 \mathrm{~h}$ after transfection) probed with neoepitope antibodies to $\mathrm{Htt}$ cleavage products

by caspase-3 yields a $70 \mathrm{kDa}(80 \mathrm{kDa}$; expanded $\mathrm{Htt})$ fragment and $75 \mathrm{kDa}(85 \mathrm{kDa}$; expanded $\mathrm{Htt})$ fragment (sites at D513, D552), while caspase- 6 cleavage yields an $80 \mathrm{kDa}$ (90 kDa; expanded Htt) fragment (cleavage site at D586). ${ }^{36}$ As shown in Figure 1b,c, caspase-2 is also capable of cleaving $\mathrm{Htt}$ to generate a cleavage product at approximately $75 \mathrm{kDa}(85 \mathrm{kDa}$; expanded $\mathrm{Htt})$, which corresponds to cleavage at D552. Comparison of $\mathrm{Htt}$ cleavage by caspase$2,-3$, and caspase- 6 with various caspase-resistant forms of $\mathrm{Htt}$ (Figure 1c) demonstrates that caspase-2 cleaves at D552 in Htt3949-138 yielding an $85 \mathrm{kDa}$ cleavage product. This cleavage product is slightly smaller than the caspase-6generated cleavage product and common to one of the cleavage products generated by caspase-3. Caspase-2, -3 , 
and -6 cleave Htt with similar efficacy as demonstrated by densitometry (Figure 1c). Of note, the cleavage of $\mathrm{Htt}$ by caspase-2 occurs at a single site, D552, unlike caspase-3, which cleaves at both D513 and D552 suggesting different substrate specificity for these two caspases. The rate of caspase-2 cleavage of $\mathrm{Htt}$ is repeat-length independent (data not shown).

To further evaluate the cleavage of $\mathrm{Htt}$ by caspases in tissue culture, we coexpressed $\mathrm{Htt}$ with cDNA constructs of caspase-2, $-3,-6,-7,-8,-9,-10,-11$, or -12 in 293 T cells. Our results demonstrate that $\mathrm{Htt}$ is cleaved by caspase- 2 only at the 552 site when probed with antibodies that detect caspasecleaved Htt fragments (neospecific antibodies to cleavage sites at 513 and 552) (Figure 1d). ${ }^{31}$ These results indicate that, in vitro, caspase-2 cleaves $\mathrm{Htt}$ at amino acid 552 and correlates with our recent results demonstrating that $\mathrm{Htt}$ is also cleaved in vivo at the D552 caspase consensus site in pyramidal cortical neurons of YAC72 mice and HD brains. ${ }^{31}$ However, these results do not necessarily explain how this cleavage event is initiated in vivo. We hypothesized that this cleavage event may require the formation of cell-death complexes and therefore $\mathrm{Htt}$ might be involved in interactions directly or indirectly with caspases. To explore the hypothesis that $\mathrm{Htt}$ is specifically recruited into a protein complex, we carried out the following immunoprecipitation experiments.

\section{Immunoprecipitation of $\mathrm{Htt} /$ caspase cell-death complexes}

We have previously shown that expression of disease proteins with expanded polyglutamine repeats are able to induce cell death in established cell lines, including COS-7 and 293T cells. ${ }^{26,27,34,35}$ We carried out our initial coimmunoprecipitations with caspases and $\mathrm{Htt}$ in 293T cells. We cotransfected 293T cells with constructs encoding either 15 or 138 polyglutamine repeats of full-length $\mathrm{Htt}$ or with an $\mathrm{N}$ terminal truncated form of $\mathrm{Htt}$ (1955-15 and 1955-128; amino acids 1-548 of $\mathrm{Htt}$ ) and a corresponding epitope-tagged caspase. At $48 \mathrm{~h}$ after transfection, the cells were harvested and immunoprecipitation was carried out using epitopecoupled (HA or FLAG) or caspase antiserum-coupled agarose beads. The expression of each $\mathrm{Htt}$ construct in the total cell lysates (TL) prior to immunoprecipitation (IP) is shown by Western analysis in Figure $2 \mathrm{a}-\mathrm{d}$ (left panel). The expression of each caspase prior to immunoprecipitation was also confirmed by Western analysis. Transfection of the truncated form of Htt1955-15 and Htt1955-128 into 293T cells resulted in a band of relative molecular mass of 75 or $85 \mathrm{kDa}$ for proteins containing 15 and 128 glutamines, respectively (Figure 2a, left panel). Transfection of full-length $\mathrm{Htt} 15$ and $\mathrm{Htt138}$ resulted in the expression of a protein with relative molecular mass of $348 \mathrm{kDa}$ (Figure $2 \mathrm{a}$, left panel). When extracts from cells transfected with caspase- 2 and various $\mathrm{Htt}$ constructs were immunoprecipitated with caspase-2 specific antiserum coupled to agarose beads, both the full-length expanded $\mathrm{Htt}$ protein and the $85 \mathrm{kDa} \mathrm{Htt} \mathrm{fragment} \mathrm{were} \mathrm{pulled}$ down (Figure $2 \mathrm{a}$, right panel). Cell extracts expressing Htt138 showed greater interaction with caspase-2 than $\mathrm{Htt} 15$ (Figure 2a, right panel), indicating that $\mathrm{Htt}$ interaction with caspase-2 is polyglutamine repeat-length dependent. $\mathrm{Htt}$ constructs with 15 (Htt15), 44 (Htt44), and 80 (Htt80) polyglutamine repeats in 293T cells confirmed that the caspase-2/Htt interaction is repeat dependent (Figure 2e). The amount of Htt protein immunoprecipitating with caspase2 gradually increased with increasing polyglutamine length. Equal amounts of caspase-2 were pulled down and inputs were equal (data not shown). Densitometry revealed an 11.7fold increase for $\mathrm{Htt} 44$, and a 19-fold increase for Htt80 relative to $\mathrm{Htt} 15$ in binding caspase-2. Control experiments with beads or preimmune serum were negative for the interaction.

Similar experiments were carried out for caspase-6, -7, -8, -9 and -3 , as shown in Figure 2b, c, d. Immunoprecipitation of caspase-7 pulled down both full-length $\mathrm{Htt}$ (Figure $2 \mathrm{~b}$, right panel) and the $85 \mathrm{kDa} H \mathrm{tt}$ fragment (Figure $2 \mathrm{~b}$, right panel). Immunoprecipitation of caspase- 6 extracted the $85 \mathrm{kDa}$ fragment of Htt (Figure 2b, right panel), but not the full-length protein (Figure $2 \mathrm{~b}$, right panel). Cell extracts expressing $\mathrm{Htt}$ with 138 repeats yielded the same amount of immunoprecipitated protein as $\mathrm{Htt}$ with 15 repeats demonstrating that $\mathrm{Htt}$ binding to caspase-7 and -6 is repeat independent (data not shown). Htt did not coimmunoprecipitate with caspase-9 (Figure 2b, right panel), caspase-8 (Figure $2 \mathrm{c}$ ), or caspase-3 (Figure $2 \mathrm{~d}$ ). These results indicate that only specific caspases are capable of forming complexes with $\mathrm{Htt}$.

To confirm the interaction between caspase- 2 and $\mathrm{Htt}$ was physiological and not due to overexpression of the proteins in cell culture, we carried out immunoprecipation experiments from YAC72 transgenic and control mouse cortex. Immunoprecipitation of $\mathrm{Htt}$ pulled down caspase-2 (Figure 2f). It should be noted that the immunoprecipitation of $\mathrm{Htt}$ brings down both the endogenous mouse $\mathrm{Htt}$ and the human $\mathrm{Htt} 72$. $\mathrm{Htt} 72$ is expressed at less than $50 \%$ the endogenous levels of mouse $\mathrm{Htt}$. Our results suggest $\mathrm{Htt}$ exists in a complex with caspase-2 under physiological conditions. Interestingly, we have shown that purified recombinant $\mathrm{Htt}$ (amino acids 1-520) and active caspase- 2 interact directly (unpublished data), suggesting that the prodomain of caspase-2 or the caspase cleavage site of $\mathrm{Htt}$ are not required for the interaction.

\section{Inhibition of Htt-induced polyglutamine repeat- dependent cell death by catalytically inactive caspases}

Given that specific caspases interact with $\mathrm{Htt}$, we tested whether the catalytically inactive forms of these enzymes could act as dominant negatives inhibitors of HD-mediated striatal cell death. We utilized dominant-negative caspases rather than caspase knockout mice since it has been demonstrated that compensatory caspase pathways are utilized in these models. ${ }^{37}$ We developed a transient transfection system whereby primary rat striatal neurons expressed green fluorescent protein (GFP) and full-length $\mathrm{Htt}$ with normal repeat length (Htt15) or an expanded polyglutamine stretch (Htt138). ${ }^{35}$ Expression of $\mathrm{Htt} 138$, but not $\mathrm{Htt} 15$, induced cell death in the cultured striatal neurons (Figure $3 a$ ). Cell body shrinkage, nuclear condensation, and neurite retraction were prominent features of these dying neurons 

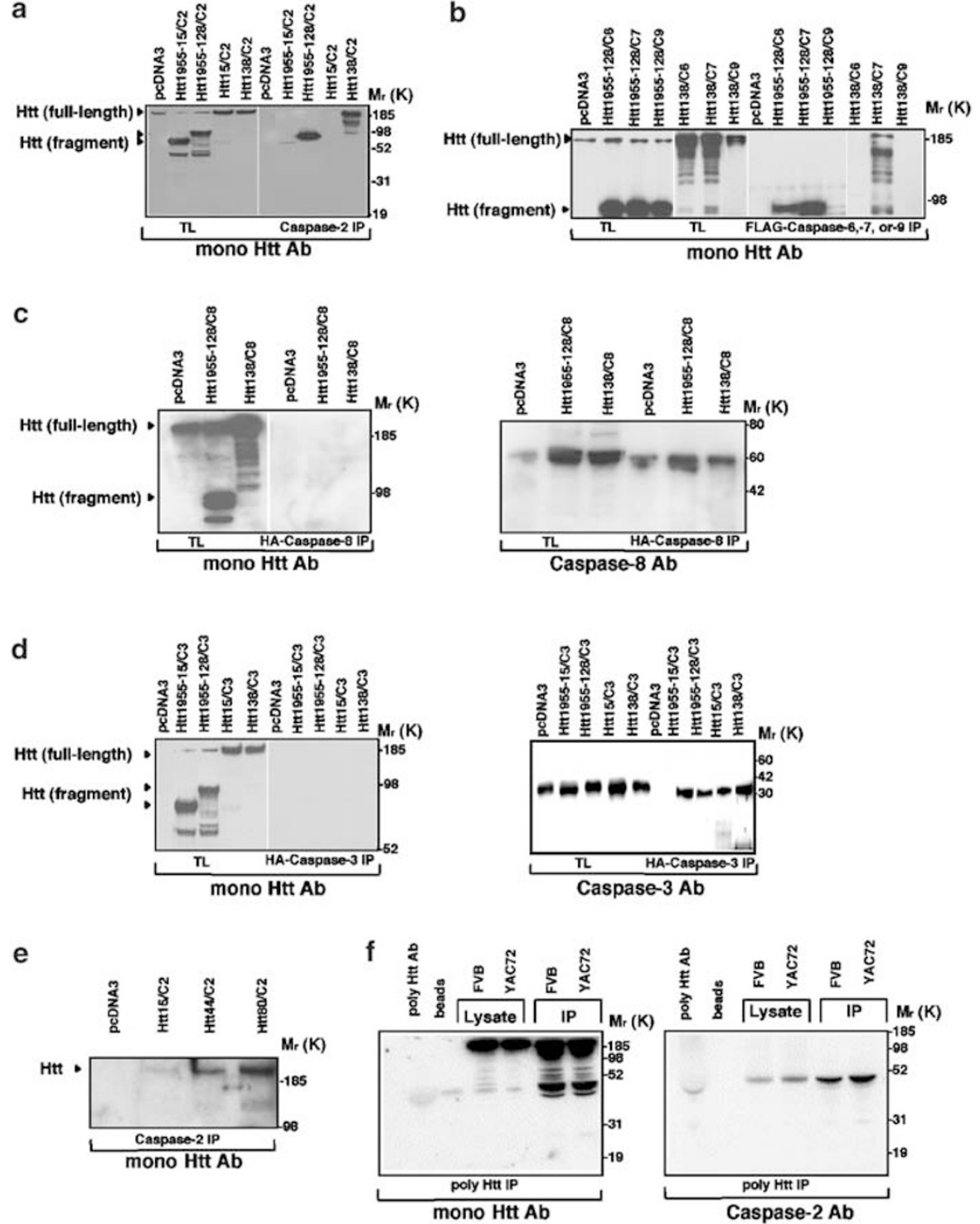

Figure 2 Full-length $\mathrm{Htt15}$ and $\mathrm{Htt} 138$ coimmunoprecipitates with caspases-2 and -7. (a) 293T cells cotransfected full-length $\mathrm{Htt}$ (Htt15), full-length $\mathrm{Htt}$ with glutamine expansion (Htt138), N-terminal fragment (Htt1955-15), N-terminal fragment with glutamine expansion (Htt1955-128), and pcDNA3-caspase-2. The total lysate prior to immunoprecipitation (left panel) and immunoprecipitation of caspase-2 from these extracts (right panel) were probed with Htt monoclonal antibody 2166 (Chemicon). Indicated are TL and IP. (b) 293T cells cotransfected with Htt138 or Htt1955-128, and FLAG-tagged caspase-6, -7, and caspase-9. The left panel shows the total cell lysate of the cotransfection of $\mathrm{N}$-terminal fragment of $\mathrm{Htt1955-128}$ and full-length $\mathrm{Htt}$ (Htt138) with caspase- $6,-7$, and -9 . The right panels show the results of immunoprecipitation of the respective caspases in the presence of the various $\mathrm{Htt}$ constructs. Both are probed with Htt monoclonal antibody 2166 (Chemicon). (c) Htt probed before (TL) and after immunoprecipitation of caspase-8 (IP) (left panel) with Htt monoclonal antibody 2166 (Chemicon). Caspase-8 was immunoprecipitated and probed with caspase-8 antibody (right panel). (d) Htt probed before (TL) and after immunoprecipitation of caspase-3 (IP). Caspase-3 was immunoprecipitated and probed with caspase-3 antibody (right panel). (e) 293T cells cotransfected with caspase-2 and pcDNA3, wild-type full-length huntingtin (Htt15), or mutant full-length Htt with $44(\mathrm{Htt} 44)$ or 80 ( $\mathrm{Htt80}$ ) polyglutamine repeats. Western blot analysis of caspase-2 IP probed with $\mathrm{Htt}$ monoclonal antibody 2166 . (f) Western blot analysis of control and YAC72 cortical lysates (1-year old) before (lysate) and after IP of Htt with an N-terminal polyclonal Htt antibody (left panel). Reprobing blot with caspase-2 antibody (MAB3507) demonstrates coimmunoprecipitation of caspase-2 (right panel)

(Figure $3 b$ ). Our results differ from an earlier report using primary culture because we use the full-length $\mathrm{Htt}$ construct while they used a Htt-derived fragment mostly composed of polyglutamine repeats. ${ }^{38}$ Using a primary culture model where full-length $\mathrm{Htt}$ is expressed is more relevant for evaluating the early events in HD disease pathogenesis and proteolysis.

Next, we examined whether coexpression of catalytically inactive forms of caspase-2 (C303A), caspase-3 (C163A), caspase-6 (C163A), caspase-7 (C186A), caspase-8 (C360A), or caspase-9 (C287A) inhibit cell death induced by $\mathrm{Htt138}$ in striatal neurons. These are denoted as dominant-negative caspase (DNC) in the figures. The percentage of cell death was determined at $96 \mathrm{~h}$ post-transfection by counting the number of dead (those rounded or shrunken without processes; Hoechst staining of condensed nuclei) and live (those with extensive neurites) GFP-positive neurons. Expression of inactive caspase-2 (C303A) or caspase-7 (C186A) led to a inhibition of neuronal cell death induced by 
a

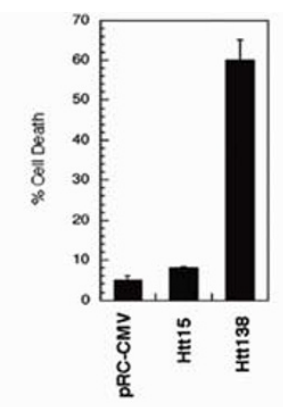

b

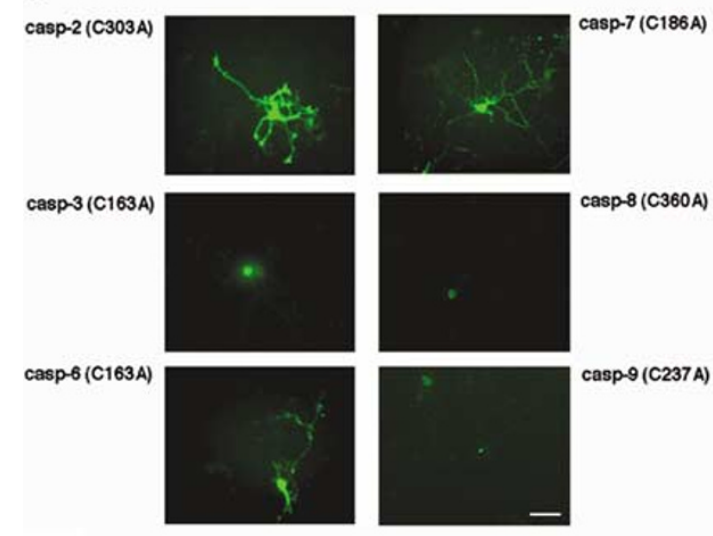

C

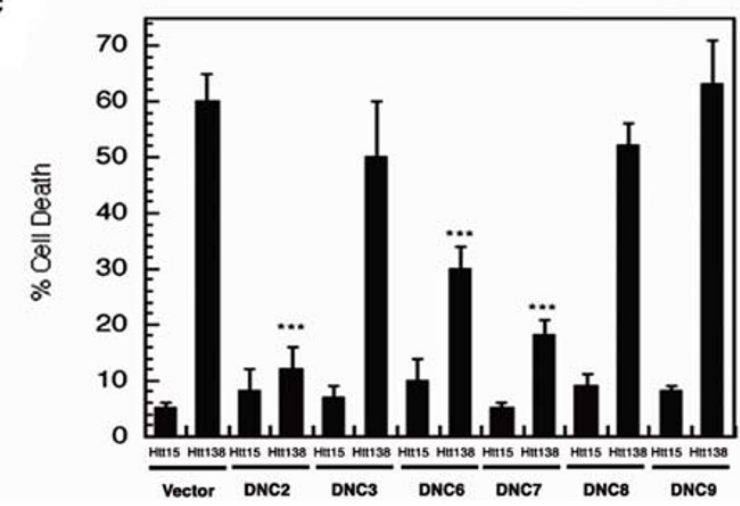

Figure 3 Inhibition of $\mathrm{Htt}$ polyglutamine repeat-induced cell death by catalytically inactive caspases. Rat (E17-E18) primary striatal neurons were transfected with vectors either full-length huntingtin (Htt15 or Htt138) or pRC$\mathrm{CMV}$ control with GFP vector included as a marker. Fluorescent micrographs at $96 \mathrm{~h}$ after transfection of both the Htt138 and GFP vector transfected striatal neurons showed cell body shrinkage, neuritic contraction, and significant cell loss, while cells transfected with $\mathrm{Htt15}$ did not. (a) Rat primary neurons were transfected with vectors encoding GFP and either full-length $\mathrm{Htt}$ (Htt15 or Htt138) and the indicated control vector, and $96 \mathrm{~h}$ after transfection the percentage of cell death was determined. S.D. was determined from three to six experiments; $\left.P<0.001{ }^{* * *}\right)$ compared to Htt138-transfected cells. (b) Caspase-2 (C303A), caspase-7 (C186A), and caspase-6 (C163A) prevented Htt138-induced cell death, while caspase-3 (C163A), caspase-8 (C360A), and caspase-9 (C237A) did not as shown by the monitoring the GFP-expressing neurons. Fluorescent micrographs at $96 \mathrm{~h}$ after transfection of $\mathrm{Htt} 138$ and the respective catalytically inactive caspase. (c) Rat primary neurons were transfected with vectors encoding GFP, full-length $\mathrm{Htt}(\mathrm{Htt15}$ or $\mathrm{Htt138)}$ and the indicated catalytically inactive caspase, and $96 \mathrm{~h}$ after transfection the percentage of cell death was determined. S.D. was determined from three to six experiments compared to Htt138-transfected cells. Scale bar $=20 \mu \mathrm{m}$. Two-factor ANOVA analysis was carried out using GraphPad Prism
$\mathrm{Htt138}$ (Figure 3b,c, $P<0.001$ ). Dominant-negative caspase6 caused a moderate inhibition of apoptosis induction by Htt138 (Figure 3b,c, $P<0.001$ ). Expression of inactive caspase-3 (C163A), caspase-8 (C360A), or caspase-9 (C287A), shown to be functional dominant-negatives in caspase-3, Fas, or bax-induced cell death, respectively (data not shown), had no effect on cell death triggered by Htt138 (Figure $3 b, c)$. These results suggest that specific caspases are involved in the Htt138-induced cell death in primary striatal neurons.

\section{Localization of caspase-2 and -7 in primary striatal cultures correlates with HD-mediated cytotoxicity and caspase recruitment}

Given catalytically inactive forms of caspase- 2 and -7 blocked $\mathrm{Htt} 138$-induced cell death, we investigated whether $\mathrm{Htt}$ localized with these caspases in primary striatal cultures derived from control and YAC72 transgenics and confirmed, under physiological conditions, that dominant-negative capase-2, -6 , and -7 blocked cell death in this cell culture model. Further, we examined whether these caspases had altered distribution during cell death given the evidence of caspase relocalization. For example, during ischemic reperfusion, caspase- 9 translocates from the mitochondria to the nucleus in some neurons. ${ }^{39}$ Caspase-2 has been localized to the Golgi complex and nucleus. ${ }^{40}$ Subcellular caspase localization can vary according to tissue and cell type. ${ }^{39}$

Expression of inactive caspase-2 (С303A) or caspase-7 (C186A) led to an inhibition of neuronal cell death in the YAC72 striatal cells (Figure 4a). Dominant-negative caspase6 caused a moderate inhibition of apoptosis in YAC72 striatal cells (Figure 4a). As shown in Figure 4b (panels a-f), caspase-2 colocalizes with $\mathrm{Htt}$ (panels $\mathrm{c}, \mathrm{f}$ ) in a punctate pattern in the cytoplasm of striatal neurons and their distal processes $(30.6 \% \pm 6.6$ of the $\mathrm{Htt}$ red channel colocalized with the caspase-2 green channel). Caspase- 7 colocalizes with $\mathrm{Htt}$ in the cytoplasm and the perinuclear zone in striatal cultures (data not shown), and during apoptotic activation, the active form of caspase-7 coexists with $\mathrm{Htt}$ in the endoplasmic reticulum (ER) in YAC72 striatal cells (Figure 4b, panels $\mathrm{i}, \mathrm{I}$ ) and not in control primary striatal cells (no immunoreactivity to activated caspase-7, not shown). Interestingly, ER stress response protein GRP78 is induced and colocalizes with $\mathrm{Htt}$ in YAC72 striatal cells as shown in Figure 4b (panels g-i). Correspondingly, $\mathrm{Htt}$ can be found colocalized with activated caspase-7 in YAC72 striatal cells (See Figure 4b, panels j-l; $96 \% \pm 3$ of the $\mathrm{Htt}$ red channel colocalized with the caspase- 7 green channel). Caspase-7 has been previously reported to localize in the ER and nucleus during apoptotic stimulation. ${ }^{41,42}$ Colocalization of caspase-2 and -7 with $\mathrm{Htt}$ is consistent with both our immunoprecipitation results and our proposed role of these caspases in the initiation of $\mathrm{Htt}$ mediated cell death.

\section{Expression of caspases in the cortex and striatum}

Initially, we immunostained adult mouse brains (Figure 5,7) and post-mortem human tissue (Figures 6,7 ) with antibodies 
A

B

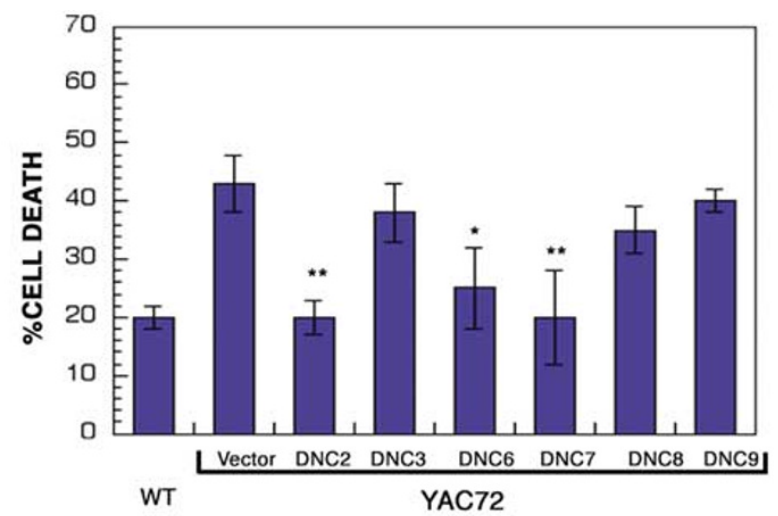

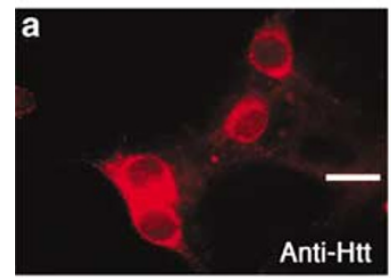
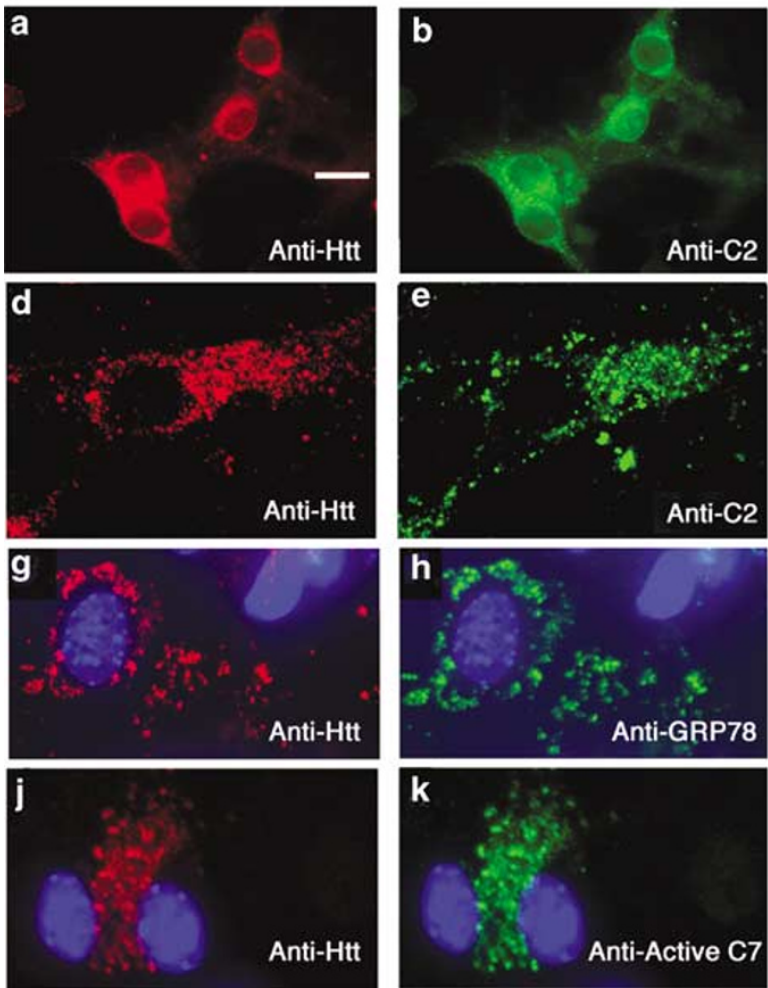
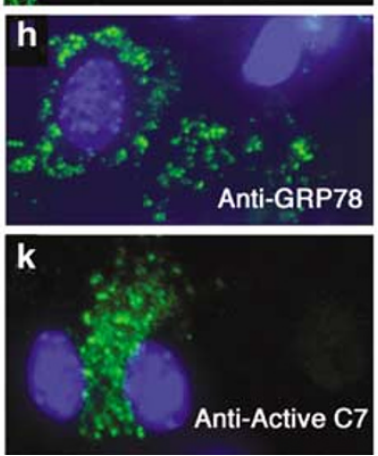
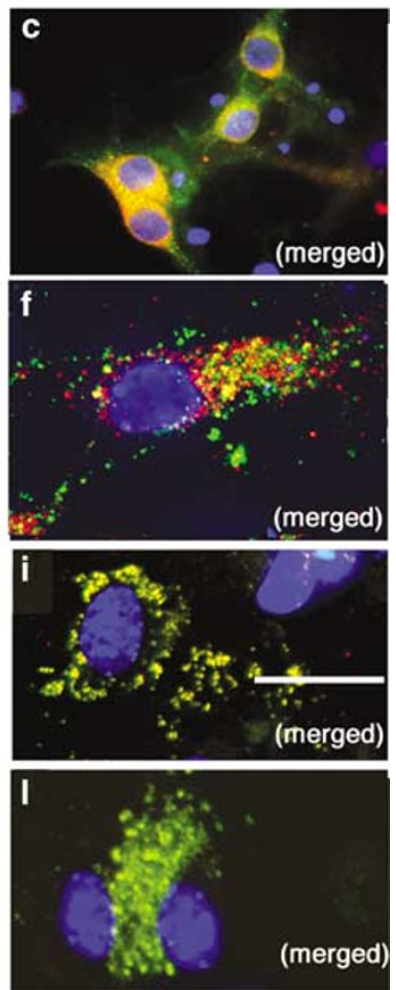

Figure 4 Location of endogenous $\mathrm{Htt}$ and caspases in primary striatal cultures. (a) Mouse primary neurons derived from YAC72 transgenic mouse (D1) were transfected with vectors encoding GFP and the indicated catalytically inactive caspase, and $96 \mathrm{~h}$ after transfection the percentage of cell death was determined. Standard deviation was determined from three to six experiments; $P<0.05\left(^{*}\right) ; P<0.01\left(^{* \star}\right) ; P<0.001\left(^{* * *}\right)$ compared to pcDNA transfected cells. (b) Primary striatal YAC72 neurons were immunostained with either an antibody to Htt (panels a, d, g, j; Texas Red) or an antibody to caspase-2 (panels b, e; FITC), an antibody to GRP78 (panel h; FITC) or an antibody to activated caspase-7 (panel k; FITC). Panels c, $\mathrm{f}$, i and I are the overlay of the first two images. The antibody used for Htt was monclonal 2170 (Chemicon). Scale bar $=20 \mu \mathrm{m}$

specific for caspase-2, $-3,-6,-7,-8$, and -9 to determine whether the regional distribution of any of these caspases correlated with the selective neuronal cell death found in HD. We focused on immunostaining in the mouse striatum and cortex (Figure 5). Interestingly, each of these caspases has a unique cell-specific pattern of expression and subcellular location. Particularly noteworthy is the comparison of the expression pattern of caspase-7 to caspase- 9 in the murine striatum (Figure $5 a, b, f, g$ ). Caspase-7 is expressed in the vulnerable medium-sized neurons (Figure $5 \mathrm{f}, \mathrm{g}$; also see Figure 7c,d), while caspase- 9 is enriched in the large cholinergic neurons (Figure 5a,b), which are spared in HD. Moreover, the murine striatal level of caspase-7 expression is elevated compared to other regions such as cortex (Figure 5f). We found the same unique pattern of cell-specific staining for caspase- 7 and -9 in the human striatum (Figure $7 c, d$ and data not shown). These findings are also consistent with our immunoprecipitation results and colocalization data, supporting our hypothesis that cell-specific expression of caspases may contribute to HD pathogenesis.

Immunostaining also shows that subsets of medium-sized striatal neurons are positive for caspase-6 (Figure 5d,e), whereas caspase- 9 immunoreactivity occurs in pyramidal cells cortical layer $\mathrm{V}$ (Figure $5 \mathrm{~h}$ ) and caspase-8 is ubiquitously expressed (Figure 5i,j). Since the pyramidal cells in cortical layer $\mathrm{V}$ produce trophic factor (BDNF) that undergoes 

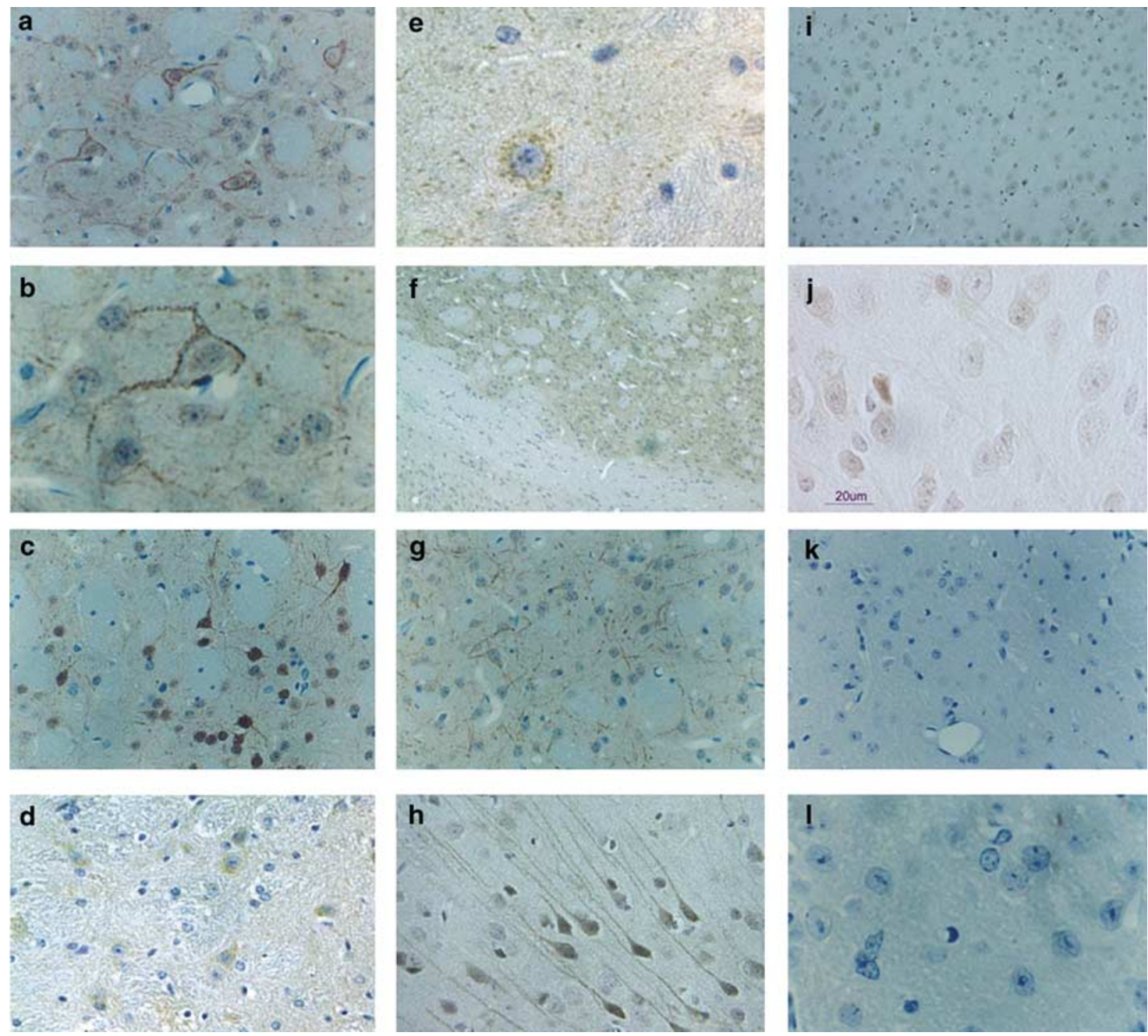

Figure 5 Immunohistochemical analysis of caspase-6, -7, -8, and caspase-9 in mouse striatum and cortex. (a, b) Capase-9 immunostaining of the large cholinergic cells of the striatum exhibit an organellar pattern of staining $(\times 400, \times 1000)$. (c) Calbindin immunostaining denotes the medium-sized cells of the striatum $(\times 400)$. (d, e) Caspase- 6 staining shows that a subset of medium-sized striatal neurons is positive for this caspase $(\times 400, \times 1000)$. (f, $\mathbf{g})$ Caspase-7 immunostaining demonstrates enrichment of this caspase in the striatum relative to the cortex and other regions of the brain $(\times 100)$ and specific staining in the medium spiny neurons $(\times 400)$. (h) Caspase-9 stains pyramidal cells in the cortex $(\times 400)$. $(\mathbf{l}, \mathbf{j})$ Caspase-8 stains ubiquitously throughout the cortex and striatum in many cell types $(\times 100$, $\times 600$ ). Results were confirmed by immunostaining with two separate anticaspase antisera. (k, I) Controls for nonspecific immunostaining included substitution of the primary antibody with preimmune serum or antigen-preadsorbed serum and were negative in all tissues. Only two examples are presented here $(\times 400, \times 1000)$

anterograde transport to the striatum and these cortical neurons degenerate in HD, the high expression of caspase9 may be important in the cortical neuropathology. These immunostaining results support the concept that cell-specific expression of caspases may contribute to HD neuropathology and disease progression. Additional in vivo evidence from human post-mortem HD tissue supporting the participation of specific caspases in HD is described below.

\section{Detection of activated caspase- 3 and -6 in distinct cell populations in human HD striatum}

To determine if caspases are activated in $\mathrm{HD}$, we evaluated whether the downstream caspase -3 and -6 are present at the sites of neuronal degeneration in human post-mortem striatal tissue. These antibodies react preferentially with the activated form of the caspases. Using an antibody to activated caspase-
3, we found that cells in the caudate of post-mortem HD were immunopositive (Figure 6a), while aged-matched controls were devoid of immunoreactivity (Figure 6k). The caspase-3 immunoreactivity localized to the nucleus in these cells. Double labeling with neuronal marker MAP2 (red) and activated caspase-3 (brown) showed no colocalization (Figure 6b). Double labeling with astrocytic marker glial fibrillary acidic protein (GFAP) (red) demonstrated that the cells immunopositive for activated caspase- 3 (brown) in the caudate were all GFAP-immunoreactive astrocytes (Figure 6c). For comparison, single labeling of GFAP astrocytic marker (Figure 6d) and neuron marker MAP2 (Figure 6h) are shown. One of the hallmarks of HD pathology is the extensive gliosis found within the striatum. It is interesting that many of the glial cells contain high levels of activated caspase- 3 and these cells are terminal deoxynucleotidyl transferase-mediated dUTP nick-end labeling (TUNEL) positive. ${ }^{25}$ Conversely, using an antibody that 

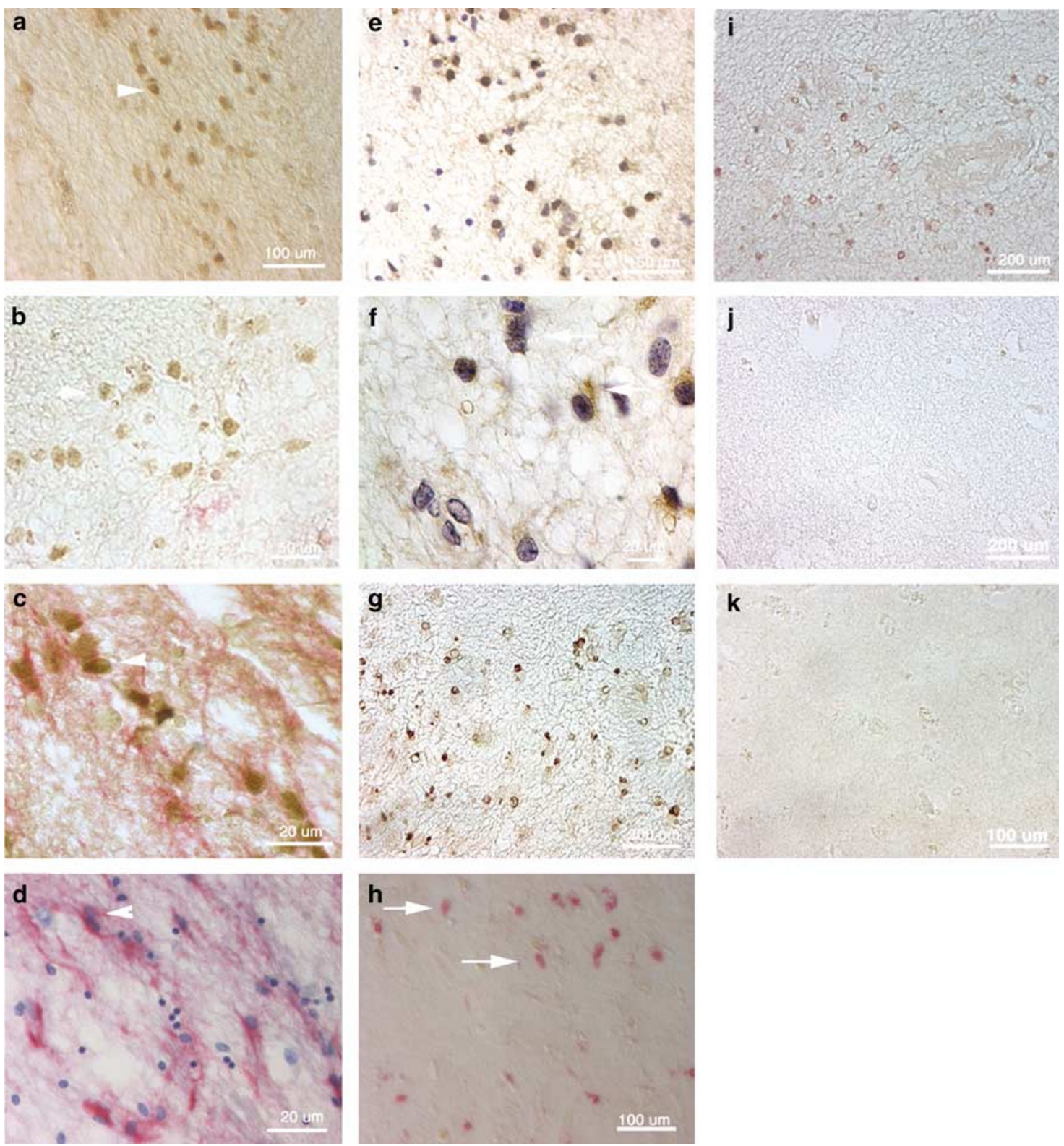

Figure 6 Immunoreactivity of activated caspase-3 in glia and activated caspase-6 in dying neurons and glia in caudate nucleus of HD brain. Frozen sections from HD $(n=3)$ and aged-matched control patients were probed with polyclonal antibody to activated caspase-3. (a) Degenerating cells in the caudate immunoreactive to activated caspase-3 are found in HD samples, but not in (k) age-matched controls. (b) Double-label immunostaining with activated caspase-3 (brown) and MAP2 (red) show only a few neurons are double labeled. (c) Double-label immunostaining of activated caspase-3 (brown) with GFAP (red) show colocalization. (d) GFAP (red) single-label immunostaining. (e, f) HD sections were probed with activated caspase-6 antibody in the caudate. (j) A representative age-matched control stained with activated caspase-6 staining is shown in the caudate. (g) Double-label immunostaining of activated caspase-6 (brown) with calbindin (red) show colocalization. Comparison of serial sections stained with (h) MAP2 or (i) calbindin antibody show localization of caspase-6 immunoreactivity with either neuronal marker. Controls for nonspecific immunostaining also were performed for all tissues, including use of preimmune serum and antigen-preadsorbed serum. VECTOR Red substrate kit was used for double-labeling experiments according to the manufacturer's instructions. Glial cells are denoted with an arrowhead and neurons with an arrow

preferentially recognizes activated caspase- 6 , we found that medium-sized neurons and glia in the caudate were immunoreactive to this antibody in post-mortem HD tissue (Figure $6 e, f)$, while aged-matched controls were devoid of immunoreactivity (Figure 6j). These results support the relevance of caspase-mediated cleavage in vivo, particularly in the vulnerable medium-sized neurons of the caudate. Double labeling with antibody to activated caspase- 6 (brown) and the neuronal marker calbindin (red) indicated that most of the cells immunoreactive to the caspase- 6 antibody were neurons (Figure $6 \mathrm{~g}$ ). For comparison, single labeling of neuronal marker MAP2 (Figure 6h) and neuronal marker calbindin (Figure 6i) are shown. These results show distinct populations of cells in the brain activate different caspases and suggests that the majority of the dying neurons in the HD caudate contain activated caspase- 6 , while glial cells contain high levels of activated caspase-3. The potential caspases involved in initiating HD neurodegeneration are described below. 

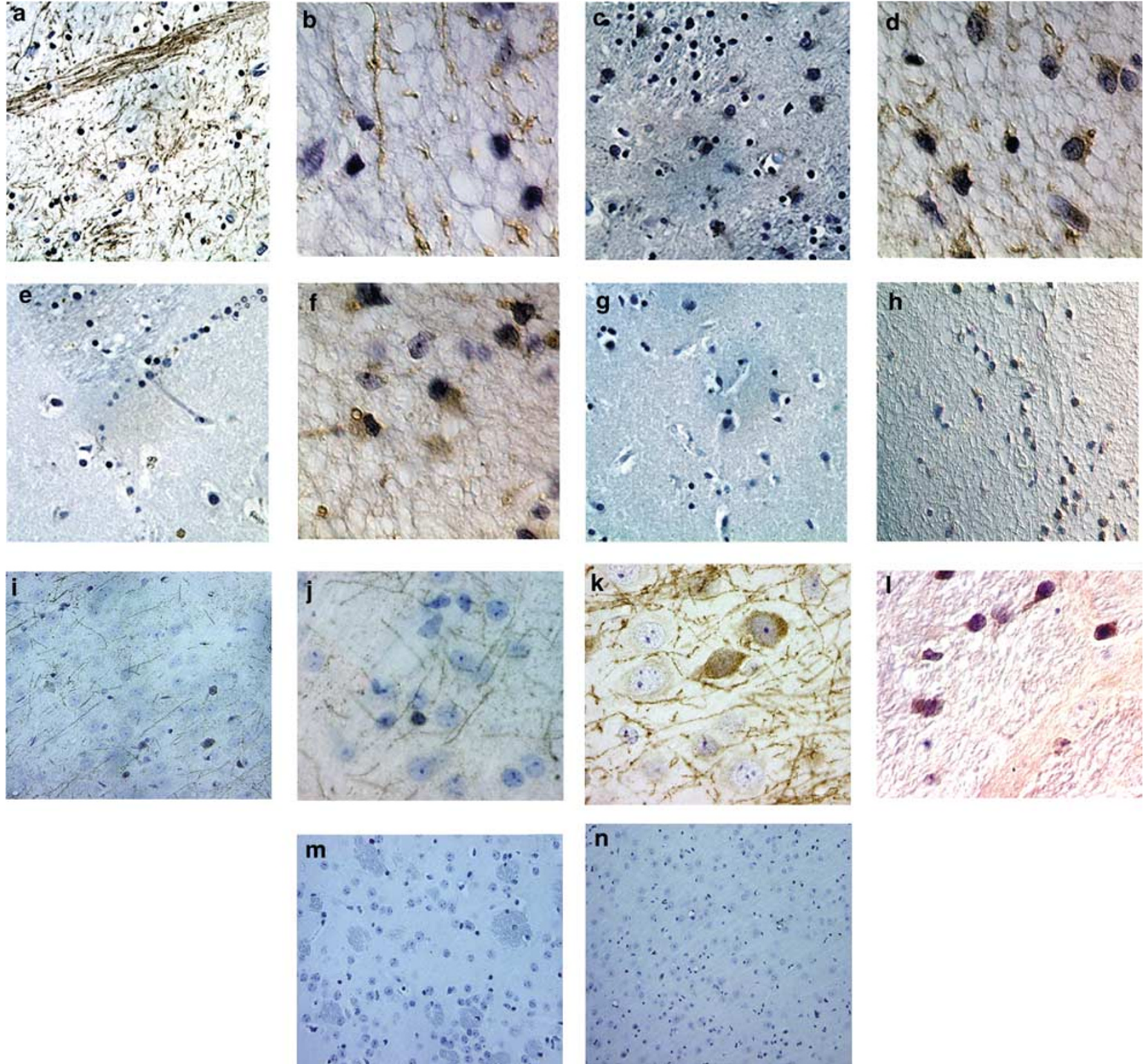

Figure 7 Caspase-2, -6, and caspase-7 immunoreactivity in post-mortem HD tissue and the YAC72 transgenic mouse brain. Fiber bundles and processes of degenerating caudate neurons in human HD brain show intense $(\mathbf{a}, \mathbf{b})$ caspase-2 immunostaining compared to (e) aged-matched control. Medium-sized neurons in the caudate nucleus display enhanced $(\mathbf{c}, \mathbf{d})$ caspase-7 immunostaining $(\times 400$ and $\times 1000)$ in post-mortem HD tissue compared to controls (not shown). (f) Mediumsized caudate neurons in the post-mortem HD caudate nucleus are immunoreactive to caspase-6 $(\times 1000)$ compared to controls (not shown). (h) Medium-sized neurons in the caudate are immunoreactive to antibody raised against cleaved caspase-7 $(\times 1000)$ for post-mortem HD tissue compared to $(\mathbf{g})$ controls. All results were confirmed by immunostaining with at least two independent anticaspase antisera and by verifying specificity via Western analysis to recombinant caspases and to endogenous caspases in cell lysates (data not shown). (i-k) Intense caspase-2 immunostaining also occurs in neuritic profiles and neurons of the cortex and striatum of YAC72 transgenic mouse YAC72 $(\times 200, \times 600, \times 1000$, respectively) compared to $(\mathbf{m}, \mathbf{n})$ age-matched control striatum and cortex. (I) Caspase-7 immunoreactivity in the striatum of the YAC72 transgenic mouse $(\times 1000)$. Controls for nonspecific immunostaining also were performed for all tissues, including the use of preimmune serum and antigen-preadsorbed serum and each control showed no immunoreactivity

\section{Enhanced immunoreactivity of caspase-2, -6, and -7 in post-mortem HD tissue and a transgenic HD mouse model}

Since we found that full-length $\mathrm{Htt}$ interacts with caspase-2 and -7 , we evaluated whether brains from cases of $\mathrm{HD}$ (grade 3; $n=3$ ) had altered expression of these two caspases when compared to healthy aged-matched controls $(n=3)$. Caspase-2 is expressed in the neuritic profiles (possibly axons) of the HD striatum (Figure 7a,b), but not in control tissue (Figure 7e). The neuronal processes are swollen in appearance, rich in caspase-2 immunoreactivity. As shown in Figure $7 \mathrm{c}, \mathrm{d}$, caspase-7 immunoreactivity in post-mortem tissue from $\mathrm{HD}$ patients is dramatically enhanced in the medium spiny neurons of the caudate nucleus and neurons in the putamen (data not shown) when compared to age-matched controls (Figure $7 \mathrm{~g}$ ). The increased caspase-7 immunoreactivity seen in the perikarya of the medium spiny neurons (Figure 7d) is at 
the site of caspase- 6 activation (Figure $6 e, f$ ) in the caudate of $\mathrm{HD}$ patients. As shown in Figure $7 \mathrm{f}$, caspase- 6 immunoreactivity is enriched in the site of neurodegeneration in the caudate of HD patients. Since the enhanced immunoreactivity of caspase-7 and -2 does not prove that these caspases have been activated during HD cell death, we utilized an antibody that recognizes only the cleaved form of caspase-7. As shown in Figure $7 \mathrm{~h}$, a number of medium-sized neurons stain positively for activated caspase-7 in HD tissue and not in controls (data not shown), indicating the direct activation of caspase-7 in HD brain.

Since human HD tissue has varying post-mortem intervals, we evaluated our hypothesis in a transgenic mouse model of HD overexpressing wild-type or mutant full-length Htt (YAC18 and YAC72) under the control of the human $\mathrm{Htt}$ promoter. This transgenic mouse model shows selective loss of medium spiny neurons in the striatum, translocation of $\mathrm{N}$-terminal fragments to the nucleus, gliosis in the striatum, and loss of neurons in the cerebral cortex by 1 year of age. ${ }^{30}$ As shown in Figure 7, immunostaining for caspase-2 (panels $\mathrm{i}-\mathrm{k}$ ) and caspase-7 (panel I) in mouse YAC72 transgenics (1 year of age) was enriched in the striatum and cortex when compared to YAC18 age-matched control (panels $m, n$ ). Similar to that found in HD post-mortem tissue, caspase-2 was found in the neuritic profiles of the striatum and cortex of the HD transgenic mouse model (Figure 7i-k). We also immunostained for caspase-8 and -9 where we found no change in immunoreactivity of the striatum between the mouse YAC72 transgenic and the agematched YAC18 controls (data not shown). Using an antibody to activated caspase-9, we found a number of cortical neurons immunoreactive only in the YAC72 (data not shown). These data further substantiate the involvement of specific caspases in the progression of HD disease in distinct neuronal populations, and support a critical role for caspase-2.

\section{Caspase-2 expression is modulated by BDNF levels}

Zuccato et al. ${ }^{33}$ reported that striatal BDNF levels are regulated by wild-type $\mathrm{Htt}$ protein in the cortical projection neurons. BDNF mRNA is not present in the striatum and therefore the supply of BDNF is controlled by corticostriatal projection neurons. Since mutant Htt lowers BDNF levels in YAC72 mice, we tested whether the enhanced immunoreactivity of caspase-2 in the cortical and striatal neurons in this model could be due to altered BDNF levels and whether these alterations preceded the onset of disease progression. It has been shown in mouse sympathetic neurons that caspase- 2 is required for trophic factor deprivation (NGF)-induced death. ${ }^{37}$ We first analyzed whether exogenous BDNF altered caspase gene transcription. The relative expression of caspases was determined by quantitative polymerase chain reaction (PCR) in the presence and absence of BDNF in primary striatal neurons (Figure 8a). These studies revealed that the caspase-2 transcript is dramatically increased in the absence of BDNF, while no significant changes were observed for transcripts encoding caspase-1, $-3,-7,-8$, or -9 . Caspase- 6 and -12 are downregulated.

We therefore evaluated whether the transcription of caspase-2 was altered in presymptomatic YAC72 mice. Using
RT-PCR, we found that caspase-2 mRNA was elevated in the cortex and striatum of YAC72 mice, compared with agematched wild-type littermates (3 months, Figure $8 b$ ). Samples run in parallel probing for $\beta$-actin mRNA show no difference in expression (Figure $8 \mathrm{~b}$ ). These results are consistent with the enhanced immunoreactivity of caspase-2 found both in YAC72 mice and HD tissue along with a 1.5-fold increase in protein expression as detected by Western analysis (data not shown). Levels of BDNF gene transcription (exon II-IV mRNAs) were also measured in presymptomatic YAC72 mice and compared with age- and sex-matched wild-type littermates (3 months, Figure $8 \mathrm{c}$ ). As described previously in 9-month-old YAC72 mice, ${ }^{33}$ exon II, exon III, and IV mRNA are decreased in YAC72 (3 month) when compared to agematched wild-type littermates ( 3 month) in the cortex.

\section{Discussion}

We have previously shown that the proteolytic processing of $\mathrm{Htt}$ by caspases and cleavage of $\mathrm{Htt}$ in vivo occurs at amino acid 552. ${ }^{26-29,43}$ In the present work, we demonstrate that specific caspases bind to Htt. The caspases that interact with $\mathrm{Htt}$ are enriched and activated in the vulnerable cell types in the striatum and cortex and therefore our work offers some potential insight into the selective neuronal cell death found in HD. Our observations support a model whereby the interaction with caspases and the subsequent proteolytic processing of $\mathrm{Htt}$ contributes to neuronal cell death in several distinct steps. First, BDNF levels are reduced in the cortex and striatum and this correspondingly increases expression of caspase-2. Second, full-length $\mathrm{Htt}$ with a polyglutamine expansion is inappropriately recruited and bound to the initiator caspase-2. Since caspase-2 and $\mathrm{Htt}$ colocalize abundantly in the neuronal processes and axonal terminals, this binding would act as a seed to induce neuritic degeneration as $\mathrm{Htt}$ is cleaved to yield cytotoxic products. The $\mathrm{N}$ terminal product generated from caspase cleavage has been shown to associate with synaptic vesicles and inhibit glutamate uptake. ${ }^{44}$ Since the binding of full-length $\mathrm{Htt}$ to caspase-2 is repeat dependent, an apoptotic initiation event need not occur to start a caspase-dependent amplification process. However, several factors such as lower BDNF levels in HD patients and transgenic mouse models may contribute to a feedback loop of caspase initiation and amplification. Lower BDNF levels will increase caspase-2 expression and caspase-2 is known to play a critical role in cell death stimulated by trophic factor deprivation in neurons. ${ }^{37} \mathrm{Sec}-$ ondly, and perhaps simultaneously, caspase-7, which is specifically expressed in the medium-sized neurons and enriched in the striatum, would bind full-length $\mathrm{Htt}$. With the association of caspase-2 and -7 with $\mathrm{Htt}$, the activity of additional caspases (particularly caspase-6) would accelerate the production of $\mathrm{Htt}$ fragments and result in the eventual induction of apoptosis both in the neuronal processes and somata. Active caspase-7 colocalizes with $\mathrm{Htt}$ in the ER recruiting Htt during apoptotic cell death and further amplifies the cell-death process.

Support for our proposed model is as follows. We have found that a specific subset of caspases interact with $\mathrm{Htt}$. 
a

BDNF

$\beta$-actin casp1 casp2 casp3 casp6 casp7 casp8 casp9 casp11 casp12

str
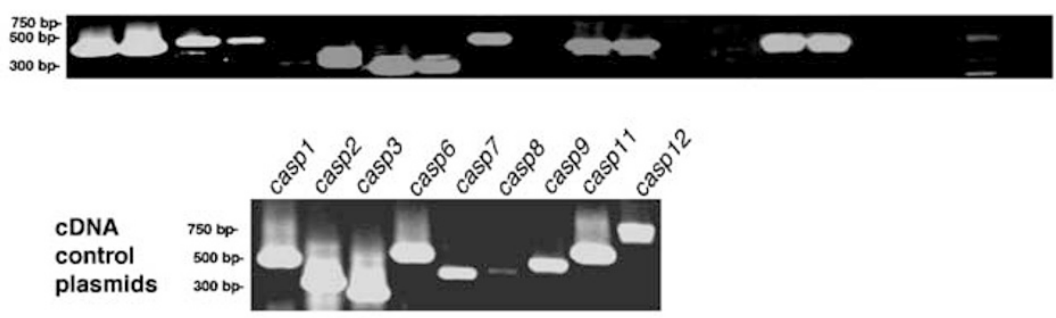

b

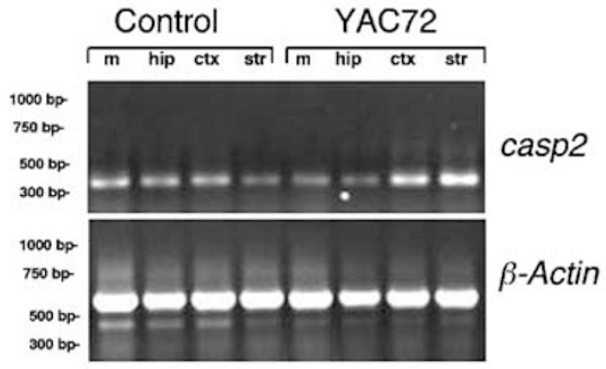

c

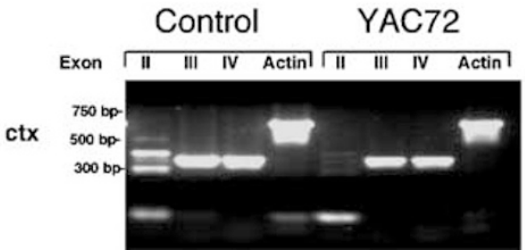

$B D N F$

Figure 8 Caspase-2 mRNA is upregulated in presymptomatic YAC72 transgenic mice, and BNDF levels modulate caspase-2 expression. (a) Ethidium bromidestained gels of RT-PCR analysis of caspase-1, $-2,-3,-6,-7,-8,-9,-11$, and -12 of primary striatal cells treated with BDNF or anti-BDNF (upper panel) run in parallel with $\beta$-actin mRNA (upper panel). cDNA controls for each caspase and their respective primers are shown as a positive control (lower panel). (b) The upregulation of caspase-2 in the cortex and striatum of YAC72 mice, compared with age- and sex-matched wild-type littermates ( 3 months, upper panel). Samples run in parallel with $\beta$ actin mRNA show no difference in mRNA levels (lower panel). The tissue regions dissected are the following: cortex (ctx), striatum (str), hippocampus (hip), and midbrain (m). (c) Levels of BDNF gene transcription were measured in presymptomatic YAC72 mice and compared with age-matched wild-type littermates (3 months). Levels of BDNF exon II-IV mRNAs were measured in the cortex as described in Zuccato et al. ${ }^{33}$ As described previously in 9-month-old YAC72, exon II mRNA is not detected, and exons III and IV are decreased in YAC72 (3 month) when compared to age-matched wild-type littermates ( 3 month). The results were repeated in triplicate. It is important to note that caspase- 6 is downregulated by the absence of BDNF. However, we found no change in mRNA for caspase-6 when comparing YAC72 to control (data not shown)

Those particular caspases demonstrate increased immunoreactivity in the brains of HD patients, cell-specific expression in the medium-spiny neurons of the striatum and cortex, and increased immunoreactivity in a full-length transgenic mouse model of HD. These same caspases are required for cell death induced specifically by expanded polyglutamine $\mathrm{Htt}$ in striatal neurons in culture. Our utilization of a dominantnegative caspase expression system may be preferable to caspase knockout primary cultures since compensatory activation of other caspases in response to the removal of the gene have been reported. ${ }^{37}$

Our results also indicate an important role for caspase-2dependent cell death in the etiology of HD. Caspase-2 interacts with $\mathrm{Htt}$ in a polyglutamine-dependent fashion as shown by greater binding for $\mathrm{Htt} 138$ than for $\mathrm{Htt} 15$, and then cleaves $\mathrm{Htt}$ to liberate a cytotoxic fragment. Caspase-2 is also critical for expanded polyglutamine $\mathrm{Htt}$-induced striatal neuronal cell death, since overexpression of a catalytic caspase-2 mutant blocks Htt-induced cell death. Furthermore, caspase-2 immunoreactivity is markedly increased in the neurites of striatal and cortical neurons in both HD patients and the YAC72 transgenic mouse model of HD. Importantly, the lower levels of BDNF increase the expression of caspase-2.

Although caspase-7 also interacts with $\mathrm{Htt}$, its interaction does not appear to be polyglutamine length dependent. Caspase-7 is capable of cleaving $\mathrm{Htt}$ and a catalytic mutant of caspase-7 blocks Htt-induced death of striatal neurons in primary culture. In contrast to caspase- 2 and -7 , caspase- 6 may have a downstream role, since it does not interact with full-length $\mathrm{Htt}$, but does interact with the cleaved $\mathrm{Htt}$ fragment. Thus, caspase- 6 may enhance the proapoptotic effect of the fragments generated by caspase- 2 and -7 , since a catalytic mutant of caspase- 6 has an inhibitory effect on Htt-induced striatal neuronal cell death. Since caspases interact with $\mathrm{Htt}$, cleave $\mathrm{Htt}$ to produce cytotoxic fragments, and are in turn activated by the proapoptotic effects of $\mathrm{Htt}$ fragments, mutant $\mathrm{Htt}$ has an amplifying effect on caspase activation initiating a feedback loop and activating the caspase cascade, thus potentially causing neuronal death observed in HD patient brains. 
The finding that caspase- 6 coimmunoprecipitates with an $\mathrm{Htt}$ fragment but not with full-length Htt supports the notion that caspase cleavage may lead to a conformational change in $\mathrm{Htt}$, and underscores the need to evaluate potential proteinprotein interactions both with full-length $\mathrm{Htt}$ and with physiologically relevant proteolytic fragments of $\mathrm{Htt}$. This finding may also explain the apparent differences between the report that a polyglutamine tract demonstrates interaction with caspase$8^{38}$ and our failure to identify caspase-8 interaction with fulllength $\mathrm{Htt}$ (or to identify caspase-8 requirement in $\mathrm{Htt}$-induced striatal neuronal cell death).

It is important to note that, although there is evidence for caspase cleavage of $\mathrm{Htt}$ in vivo, ${ }^{31}$ definitive proof for the requirement of caspase-2, $-3,-6$, and -7 in vivo will require further studies. Further, other proteases, such as calpains may also be involved. ${ }^{32}$ Nevertheless, the results presented here suggest that the interaction between caspase-2 and expanded Htt may be an appropriate target for therapeutic intervention. Further, our recent finding that caspase cleavage of both normal and expanded $\mathrm{Htt}$ occurs in vivo, with the identified 552 site as a preferred site of caspase cleavage in human HD and YAC72 transgenic mice, correlates well with our proposed role for caspase-2 in HD. ${ }^{31}$ Together, these findings have important implications for the treatment of HD. Rather than simply blocking cell death with a general caspase inhibitor, one could design molecules that specifically block the interaction of $\mathrm{Htt}$ with the caspase-2 apoptosome complex or alternately downregulate the expression of capase-2. Our findings also raise the possibility that each of the polyglutamine-repeat disease proteins interacts with caspase-specific cell-death complexes and that specificity of neuronal celldeath observed in these diseases can be correlated in part with regional caspase expression.

Our studies do not address how sequential activation of caspases early in HD pathogenesis may affect the functional and neuroanatomic effects taking place over months in neurodegenerative diseases and at this point are correlative in nature. However, it is possible that caspase activation may contribute to early cellular dysfunction and is not just a late stage event. Slowly evolving neurodegenerative diseases may be the result of cotemporal activation of cell death proteases in neuronal cell populations that occurs over weeks and months and is an upstream event. Further, the cotemporal activation of cell death proteases may occur in distinct substructures of the neuron - both soma and the axons of striatal projection neurons where local activation of distinct caspases may contribute to neuronal dysfunction and eventual death. Testing this hypothesis will require further experimentation. Interestingly, careful stereological counting of the loss of striatal and cortical cells in YAC HD mice demonstrates a direct correlation with motor dysfunction. ${ }^{45}$ Further studies are required to address the relative contribution of caspases to early and late events in HD pathogenesis.

\section{Materials and Methods}

\section{Plasmid construction}

Wild-type full-length human $\mathrm{Htt}(\mathrm{Htt} 15)$ and mutant $\mathrm{Htt}$ with 44 (Htt44), 80 ( $\mathrm{Htt80})$, and 138 ( $\mathrm{Htt138}$ ) repeats, the $\mathrm{N}$-terminal fragment encoding a 548 amino-acid fragment of wild-type $\mathrm{Htt}(\mathrm{Htt} 1955-15)$ and mutant $\mathrm{Htt}$ with 128 repeats(Htt1955-128) and the $\mathrm{N}$-terminal fragment encoding a 1212 amino-acid fragment of wild-type $\mathrm{Htt}$ (Htt3949-15) and mutant $\mathrm{Htt}$ with 138 repeats (Htt3949-138) were described previously. ${ }^{28,34,36}$ The following catalytic mutant caspases, which disable the catalytic cysteine residue, were generated using the QuikChange Site-Directed Mutagenesis Kit (Stratagene): caspase-2 (C303A), caspase-3 (C163A), caspase-6 (C163A), caspase-7 (C186A), caspase-8 (C360A), and caspase-9 (C287A).

\section{Cell culture and antibodies}

Human embryonic kidney 293T cells were grown as described previously. ${ }^{26,27}$ Transient transfections of plasmids in 293T cells were performed with Superfect reagent (Qiagen) following the manufacturer's instructions (10 $\mu \mathrm{g}$ DNA, $300 \mu \mathrm{l}$ serum-free medium, and $30 \mu \mathrm{l}$ Superfect added to a $10 \mathrm{~cm}$-dish containing $3-4 \mathrm{ml}$ of media). Control transfections with pcDNA3-GFP were carried out and showed greater than $80 \%$ transfection efficiency.

Western analysis of 293T cells transfected with human caspase-1 through caspase-12 confirmed the specificity of each antibody and the lack of crossreactivity between caspase family members. Antibody Bur49 was raised against human caspase- 9 , and Bur1890 against human caspase- 8 following the same methods. ${ }^{39}$ The specificity and affinity of these antibodies for their respective caspases were confirmed as previously described. ${ }^{39}$ Rabbit and goat polyclonal anticaspase-2 antibody (Santa Cruz, sc-625, sc-625) and rat monoclonal anticaspase-2 (Chemicon, MAB3501 and MAB3507) crossreact with mouse and human caspase-2 and were used for both IP and histology. Rabbit polyclonal antiactive caspase-3 (67341A, Pharmingen), polyclonal active caspase-3 (Cell Signaling, \#9661S), and mouse monoclonal caspase-7 antibody (Pharmingen) react with human and mouse. Anticaspase-3 antibody (Transduction Laboratories, C31720) reacts with human only. Rabbit polyclonal caspase- 6 antibody was raised against human caspase- 6 and also purchased from Upstate Biotechnology (\#06-691) reacting with human and mouse. Rabbit polyclonal active-caspase- 6 antibody (Cell Signaling, \#9761) reacts against mouse and human. Rabbit polyclonal antiactive caspase-7 (Cell Signaling, \#9491) reacts with mouse and human. Anticleaved caspase-9 antibody (BioLabs \#9501S) reacts with mouse and human. Antibodies were used according to the directions of the manufacturer. Htt neoepitope antibodies were described previously. ${ }^{31}$

\section{In vitro protein synthesis and caspase cleavage}

In vitro transcription and translation were performed using the Promega Coupled kit. The constructs (pRC-CMV3949-15; construct yielding the first 1212 amino acids of $\mathrm{Htt}$ ) and 138 glutamine repeats (pRC-CMV3949-138) were translated, and the protein products were used to assess caspase cleavage. Cleavage with caspases $-2,-3,-6,-7,-8,-9$, and -10 were performed and assessed as previously described. ${ }^{26,27}$

\section{Caspase interaction assay in cultured cells and mouse cortical tissue}

Cells were cotransfected with caspase-2, $-3,-6,-7,-8$, or -9 and $\mathrm{Htt}$ or pRC-CMV vector control only. Cell lysates of cotransfected 293T cells were prepared by incubating cells in NP40 lysis buffer $(0.1 \%$ NP40, $50 \mathrm{mM}$ Hepes, pH 7.4, $250 \mathrm{mM} \mathrm{NaCl}, 5 \mathrm{mM}$ EDTA) for $30 \mathrm{~min}$ on ice with occasional vortexing. IP was carried out by incubation with anti-FLAG M2 
agarose affinity gel (Sigma, St. Louis, MO, USA), anti-HA antibody, or anticaspase-2 agarose beads for $12 \mathrm{~h}$ to bind FLAG- or HA-tagged caspases or caspase-2, respectively. The beads were washed five times and resuspended in NP40 lysis buffer and then Laemmli sample buffer. The immunoprecipitated proteins were resolved by $10 \%$ SDS-PAGE and were transferred to polyvinylidene fluoride (PVDF) membranes for Western blotting. FLAG M2 antibody, caspase antibodies, or monoclonal $\mathrm{Htt}$ antibody (Chemicon 2166) was used for Western analysis. The immunoblots were developed with peroxidase-conjugated secondary antibody and enhanced chemiluminescence.

Cortical tissue from FVB and YAC72 mice were lysed in RIPA buffer

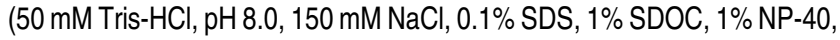
protease inhibitor (Complete Mini, Roche Molecular Biochemicals), sheered with a 26-gauge needle and clarified by centrifugation at $16000 \mathrm{~g}$ for $20 \mathrm{~min}\left(4^{\circ} \mathrm{C}\right)$. The $\mathrm{N}$-terminal rabbit polyclonal $\mathrm{Htt}$ antibody described previously ${ }^{46}$ was used for immunoprecipitation. Immunoprecipitation and Western analysis was performed as described above.

\section{Striatal cultures}

Primary cultures of striatum were prepared as described previously. ${ }^{47}$ Striata of 17- to 18-day-old Sprague-Dawley rat embryos were dissected, minced, and digested with $0.25 \%$ trypsin for $5 \mathrm{~min}$. After the addition of $10 \%$ horse serum, the tissue was triturated 15-20 times and centrifuged for $5 \mathrm{~min}(800 \mathrm{~g})$. The pellet was resuspended in MEM-PAK (UCSF Cell Culture Facility) supplemented with $30 \mathrm{mM}$ glucose, $2 \mathrm{mM}$ GlutaMAX-1 (Life Technologies), and penicillin/streptomycin (100 U/ml). The suspension was filtered through a $70 \mu \mathrm{m}$ cell strainer, and $5 \%$ horse serum (Life Technologies) was added. Cells at $2-3 \times 10^{5} / \mathrm{cm}^{2}$ were seeded on either 24-well plates or 12-mm coverslips precoated with $50 \mu \mathrm{g} / \mathrm{ml}$ of Dpolylysine. After a 30-min incubation, unattached cells were removed and the medium was replaced with glucose-enriched MEM-PAK. Cultures were fed weekly and used between 1 and 3 weeks. Striata were dissected from YAC72 and FVB controls at postnatal day 0-1 (P0-1) mice and primary cultures prepared as described above. Striatal neurons were transfected by the standard calcium phosphate method. ${ }^{47}$ The striatal neurons were exposed to calcium phosphate and DNA precipitate for $20 \mathrm{~min}$, washed twice with medium, and then cultured in fresh medium. Cells were transfected at $2-5 \%$ transfection efficiency. This initial exposure to calcium stimulated cell death in the Htt138-transfected cells and the YAC72 striatal cells. The percentage of cell death induced by fulllength $\mathrm{Htt}$ with polyglutamine expansion ( $\mathrm{Htt} 138)$ was determined by transfecting cells with $2 \mu \mathrm{g}$ of the pRC-CMV-Htt138 expression construct and $0.4 \mu \mathrm{g}$ of pEGFP-N1 (Clontech) was used as a marker. In cotransfection experiments with catalytically inactive caspase constructs encoding human caspase-2 C303A, caspase-3 C163A, caspase-6 C163A, caspase-7 C186A, caspase-8 C360A, and caspase-9 C286A, a ratio of $1: 1$ with the $\mathrm{pRC}-\mathrm{CMV}-\mathrm{Htt} 138$ expression construct was used. Apoptotic cells were identified by visual inspection of GFP-positive cells with a Nikon inverted fluorescence microscope. Hoechst 33342 was used to examine nuclear morphology and count cells. Each experiment was performed at least in triplicate, with $>300$ cells counted for each determination. BDNF (Sigma B3795) was applied to primary mouse striatal cultures for $24 \mathrm{~h}$ at $50 \mathrm{ng} / \mathrm{ml}$. Monclonal anti-human BDNF from Sigma (B5050) was applied to striatal cultures to neutralize the biological activity of endogenous BDNF. Monoclonal Htt antibody (Chemicon 2166, 2168) and rabbit GRP78 (StressGen SPA-826) was used for immunocytochemistry. ANOVA analysis with post hoc tests (via GraphPad Prism) for the data presented in Figure 4 and two-factor ANOVA analysis for Figure 3 were preformed with $P^{\star}<0.05, P^{\star \star}<0.01$, and $P^{\star \star *}<0.001$.

\section{Immunocytochemistry}

Formalin-fixed human tissue (from the Harvard Brain Tissue Resource Center), or mouse brains perfused with $4 \%$ paraformaldehyde, was paraffin embedded. YAC transgenic animals expressing human $\mathrm{Htt}$ with 72 CAG repeats were used as a source of murine tissues. Line 2511 contains 1-2 copies of the YAC72 and has been described previously. ${ }^{30}$ Mouse brains were sectioned horizontally $(8 \mu \mathrm{m})$ on the automated rotary microtome (Leica) and deparaffinized in xylene. Antigen retrieval was

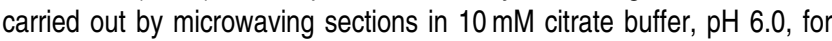
5 min at $40 \%$ power in an $1100 \mathrm{~W}$ microwave oven. Blocking was carried out in 10\% normal horse serum in TBS -for $1 \mathrm{~h}$ at room temperature. Primary antibody was diluted 1:100-1:1000 in 1\% BSA in TBS and incubated for $48 \mathrm{~h}$ at $4^{\circ} \mathrm{C}$. Rabbit lgG2 $(2 \mu \mathrm{g} / \mathrm{ml})$ or preimmune antiserum was used as a negative control. Biotinylated secondary antibody $(1: 250$, Vector) was used for incubation times of $1 \mathrm{~h}$ at $37^{\circ} \mathrm{C}$ in a humidified chamber and followed by TBS washes $(3 \times 10 \mathrm{~min})$ at RT. DAB at a final concentration of $0.25 \mathrm{mg} / \mathrm{ml}$ with $0.05 \% \mathrm{H}_{2} \mathrm{O}_{2}$ in TBS was used for developing typically for $3.5 \mathrm{~min}$ at RT. VECTOR Red substrate kit was used for double-labeling experiments according to the instructions of the manufacturer. Sections were counter stained with Mayers hematoxylin (American MasterTech).

\section{cDNA generation}

Total RNA from wild-type or transgenic cortex, hippocampus, mid-cortex, and striatum was extracted twice using Trizol (Gibco/BRL, Gaithersburg, MD,USA). cDNA was generated from $1.0 \mu \mathrm{g}$ of RNA using SuperScript II reverse transcriptase (Life Technologies, Gaithersburg, MD, USA) according to the instructions of the manufacturer.

\section{Semiquantitative PCR}

PCR parameters were $2.5 \mu \mathrm{l}$ of four-fold-diluted cDNA reaction products, $25 \mathrm{pM}$ primers, $0.5 \mathrm{mM}$ dNTPs, and $2 \mathrm{U}$ of Taq polymerase (Roche Molecular Biochemicals, Indianapolis, IN, USA) with $2.5 \mu \mathrm{l}$ of $10 \times$ buffer. Total reaction volume was $25 \mu$ l. Cycling conditions and PCR primers for BDNF exons 2, 3, 4, and 5 were as described ${ }^{33}$ As a positive control for PCR, mouse $\beta$-actin primers ( $\beta$-actin- $5^{\prime}$ : CATCGTGGGCCGCTCTAGGCACCAA and $\beta$-actin-3': CAGGGAGGAA-GAGGATGCGGCA) were used. The caspase oligos react with both mouse and human sequences and are as follows: Casp1-5': acacgtcttgccctcattatctgcaa, Casp1-3': Atggtt-gttcaaatgaaaatcgaacct; Casp2-5': tgagggag-ctcatcca-ggcca; Casp2-3': tccagtgaagtgcacattgctca; Casp3-5': aaacctcag-tggattcaaaatccattaa; Casp3-3': acacacacaaag-ctgctcc-tttgct; Casp6-5': acaagatggaccacaagaggagagga; Casp6-3': tgcagcttttggtcagcattgaggc; Casp7-5': aatgcatcatca-taaacaa-caagaactt; Casp7-3': gcagagggcctgcacaaaccagga; Casp8-5': ggatgtt-ggaggaaggcaatctgtc; Casp8-3': ttgatgatca-gacagtatccccga; Casp9-5': tcatcatcaacaatgtgaacttctgcc; Casp9-3': ggagggactgcaggtcttcag; mCASP11-5': ctggaaatggag-gaaccagaaga; mCASP11$3^{\prime}$ cgatcaatggtgggcatctgggaa; mCASP12-F2: ggaaaaatattgctggccacatt; mCASP12-3': tagtgggcatctgggt-cagttca.

\section{Acknowledgements}

LME is supported by National Institutes of Health Grant NS40251A, Huntington Disease Society of America, Hereditary Disease Foundation and the Muscular Dystrophy Association. JG is supported by a National Institutes of Health postdoctoral fellowship F32 NS043937. CW and AP are supported by Hereditary Disease Foundation Postdoctoral Fellow- 
ships. ASH is supported by MRC Canada. DB is supported by grants from the National Institutes of Health (AG12282 and CA69381). MRH is supported by Merck Frosst grants to the CMMT. MRH is also supported by the Medical Research Council of Canada, the Canadian Networks of Centres of Excellence (NCE-Genetics), and the Huntington Disease Society of America, Coalition for the Cure, and is an established investigator of the BC Children's Hospital. The tissues were provided by the Harvard Brain Tissue Resource Center that is supported in part by PHS grant number MN/NS 31862. We gratefully acknowledge Donald Nicholson and Sophie Roy for generously sharing the Htt neoepitopea antibodies for this project.

\section{References}

1. The Huntington's Disease Collaborative Research Group. (1993) A novel gene containing a trinucleotide repeat that is expanded and unstable on Huntington's disease chromosomes. Cell 72: 971-983

2. Imbert G, Saudou F, Yvert G, Devys D, Trottier Y, Garnier JM, Weber C, Mandel JL, Cancel G, Abbas N, Durr A, Didierjean O, Stevanin G, Agid Y and Brice A (1996) Cloning of the gene for spinocerebellar ataxia 2 reveals a locus with high sensitivity to expanded CAG/glutamine repeats. Nat. Genet. 14: 285291

3. Kawaguchi $\mathrm{Y}$, Okamoto T, Taniwaki M, Aizawa M, Inoue M, Katayama S, Kawakami H, Nakamura S, Nishimura M, Akiguchi I, Kimura J, Narumiya S and Kakizuka A (1994) CAG expansions in a novel gene for Machado-Joseph disease at chromosome 14q32.1. Nat. Genet. 8: 221-228

4. Koide R, Ikeuchi T, Onodera O, Tanaka $\mathrm{H}$, Igarashi $\mathrm{S}$, Endo $\mathrm{K}$, Takahashi $\mathrm{H}$, Kondo R, Ishikawa A, Hayashi T, Saito M, Tomoda A, Miike T, Naito H, Ikuta F and Tsuji S (1994) Unstable expansion of CAG repeat in hereditary dentatorubral-pallidoluysian atrophy (DRPLA). Nat. Genet. 6: 9-13

5. La Spada AR, Wilson EM, Lubahn DB, Harding AE and Fischbeck KH (1991) Androgen receptor gene mutations in X-linked spinal and bulbar muscular atrophy. Nature 352: 77-79

6. Lindblad K, Savontaus ML, Stevanin G, Holmberg M, Digre K, Zander C, Ehrsson H, David G, Benomar A, Nikoskelainen E, Trottier Y, Holmgren G, Ptacek LJ, Anttinen A, Brice A and Schalling M (1996) An expanded CAG repeat sequence in spinocerebellar ataxia type 7. Genome Res. 6: 965-971

7. Nagafuchi S, Yanagisawa H, Sato K, Shirayama T, Ohsaki E, Bundo M, Takeda T, Tadokoro K, Kondo I, Murayama N, Tanaka Y, Kikushima H, Unino K, Kurosawa H, Furukawa T, Nihei K, Inouc T, Sano A, Komure O, Takahashi M, Yoshizawa T, Kanazawa I and Yamada M (1994) Dentatorubral and pallidoluysian atrophy expansion of an unstable CAG trinucleotide on chromosome 12p. Nat. Genet. 6: 14-18

8. Orr HT, Chung MY, Banfi S, Kwiatkowski Jr TJ, Servadio A, Beaudet AL, McCall AE, Duvick LA, Ranum LP and Zoghbi HY (1993) Expansion of an unstable trinucleotide CAG repeat in spinocerebellar ataxia type 1. Nat. Genet. 4: $221-226$

9. Pulst SM, Nechiporuk A, Nechiporuk T, Gispert S, Chen XN, Lopes-Cendes I, Pearlman S, Starkman S, Orozco-Diaz G, Lunkes A, DeJong P, Rouleau GA, Auburger G, Korenberg JR, Figueroa C and Sahba S (1996) Moderate expansion of a normally biallelic trinucleotide repeat in spinocerebellar ataxia type 2. Nat. Genet. 14: 269-276

10. Sanpei K, Takano H, Igarashi S, Sato T, Oyake M, Sasaki H, Wakisaka A, Tashiro K, Ishida Y, Ikeuchi T, Koide R, Saito M, Sato A, Tanaka T, Hanyu S, Takiyama Y, Nishizawa M, Shimizu N, Nomura Y, Segawa M, Iwabuchi K, Eguchi I, Tanaka H, Takahashi H and Tsuji S (1996) Identification of the spinocerebellar ataxia type 2 gene using a direct identification of repeat expansion and cloning technique, DIRECT. Nat. Genet. 14: 277-284

11. Zhuchenko O, Bailey J, Bonnen P, Ashizawa T, Stockton DW, Amos C, Dobyns WB, Subramony SH, Zoghbi HY and Lee CC (1997) Autosomal dominant cerebellar ataxia (SCA6) associated with small polyglutamine expansions in the alpha 1A-voltage-dependent calcium channel. Nat. Genet. 15: 62-69

12. Ross CA (1995) When more is less: pathogenesis of glutamine repeat neurodegenerative diseases. Neuron 15: 493-496

13. Martin JB and Gusella JF (1986) Huntington's disease. Pathogenesis and management. N. Engl. J. Med. 315: 1267-1276
14. Hedreen JC and Folstein SE (1995) Early loss of neostriatal striosome neurons in Huntington's disease. J. Neuropathol. Exp. Neurol. 54: 105-120

15. Vonsattel JP, Myers RH, Stevens TJ, Ferrante RJ, Bird ED and Richardson Jr EP (1985) Neuropathological classification of Huntington's disease. J. Neuropathol. Exp. Neurol. 44: 559-577

16. Gutekunst CA, Levey Al, Heilman CJ, Whaley WL, Yi H, Nash NR, Rees HD, Madden JJ and Hersch SM (1995) Identification and localization of huntingtin in brain and human lymphoblastoid cell lines with anti-fusion protein antibodies. Proc. Natl. Acad. Sci. USA 92: 8710-8714

17. Sharp AH, Love SJ, Schilling G, Li SH, Li XJ, Bao J, Wagster MV, Kotzuk JA, Steiner JP, Lo A, Hedreen J, Sisodia S, Snyder SH, Dawson TM, Ryugo DK and Ross CA (1995) Widespread expression of Huntington's disease gene (IT15) protein product. Neuron 14: 1065-1074

18. Trottier $Y$, Lutz $Y$, Stevanin G, Imbert G, Devys D, Cancel G, Saudou F, Weber C, David G, Tora L, Agid Y, Brice A and Mandel J (1995) Polyglutamine expansion as a pathological epitope in Huntington's disease and four dominant cerebellar ataxias. Nature 378: 403-406

19. De Rooij KE, Dorsman JC, Smoor MA, Den Dunnen JT and Van Ommen GJ (1996) Subcellular localization of the Huntington's disease gene product in cell lines by immunofluorescence and biochemical subcellular fractionation. Hum. Mol. Genet. 5: 1093-1099

20. DiFiglia M, Sapp E, Chase K, Schwarz C, Meloni A, Young C, Martin E, Vonsattel JP, Carraway R, Reeves SA, Boyce FM and Aronin N (1995) Huntingtin is a cytoplasmic protein associated with vesicles in human and rat brain neurons. Neuron. 14: 1075-1081

21. Saudou F, Devys D, Trottier Y, Imbert G, Stoeckel ME, Brice A and Mandel JL (1996) Polyglutamine expansions and neurodegenerative diseases. Cold Spring Harb. Symp. Quant. Biol. 61: 639-647

22. Graveland GA, Williams RS and DiFiglia M (1985) Evidence for degenerative and regenerative changes in neostriatal spiny neurons in Huntington's disease. Science 227: 770-773

23. Reiner A, Albin RL, Anderson KD, D'Amato CJ, Penney JB and Young AB (1988) Differential loss of striatal projection neurons in Huntington disease. Proc. Natl. Acad. Sci. USA 85: 5733-5737

24. Sapp E, Ge P, Aizawa H, Bird E, Penney J, Young AB, Vonsattel JP and Difiglia M (1995) Evidence for a preferential loss of enkephalin immunoreactivity in the external globus pallidus in low grade Huntington's disease using high resolution image analysis. Neuroscience 64: 397-404

25. Portera-Cailliau C, Hedreen JC, Price DL and Koliatsos VE (1995) Evidence for apoptotic cell death in Huntington disease and excitotoxic animal models. J. Neurosci. 15: 3775-3787

26. Ellerby LM, Andrusiak RL, Wellington CL, Hackam AS, Propp SS, Wood JD, Sharp AH, Margolis RL, Ross CA, Salvesen GS, Hayden MR and Bredesen DE (1999) Cleavage of atrophin-1 at caspase site aspartic acid 109 modulates cytotoxicity. J. Biol. Chem. 274: 8730-8736

27. Ellerby LM, Hackam AS, Propp SS, Ellerby HM, Rabizadeh S, Cashman NR, Trifiro MA, Pinsky L, Wellington CL, Salvesen GS, Hayden MR and Bredesen DE (1999) Kennedy's disease: caspase cleavage of the androgen receptor is a crucial event in cytotoxicity. J. Neurochem. 72: 185-195

28. Goldberg YP, Nicholson DW, Rasper DM, Kalchman MA, Koide HB, Graham RK, Bromm M, Kazemi-Esfarjani P, Thornberry NA, Vaillancourt JP and Hayden MR (1996) Cleavage of huntingtin by apopain, a proapoptotic cysteine protease, is modulated by the polyglutamine tract. Nat. Genet. 13: $442-449$

29. Wellington CL, Ellerby LM, Hackam AS, Margolis RL, Trifiro MA, Singaraja R, McCutcheon K, Salvesen GS, Propp SS, Bromm M, Rowland KJ, Zhang T, Rasper D, Roy S, Thornberry N, Pinsky L, Kakizuka A, Ross CA, Nicholson DW, Bredesen DE and Hayden MR (1998) Caspase cleavage of gene products associated with triplet expansion disorders generates truncated fragments containing the polyglutamine tract. J. Biol. Chem. 273: 9158-9167

30. Hodgson JG, Agopyan N, Gutekunst CA, Leavitt BR, LePiane F, Singaraja R, Smith DJ, Bissada N, McCutcheon K, Nasir J, Jamot L, Li XJ, Stevens ME, Rosemond E, Roder JC, Phillips AG, Rubin EM, Hersch SM and Hayden MR (1999) A YAC mouse model for Huntington's disease with full-length mutant huntingtin, cytoplasmic toxicity, and selective striatal neurodegeneration. Neuron 23: 181-192

31. Wellington $C L$, Ellerby $L M$, Gutekunst $C A$, Rogers D, Warby S, Graham RK, Loubser O, van Raamsdonk J, Singaraja R, Yang YZ, Gafni J, Bredesen D, Hersch SM, Leavitt BR, Roy S, Nicholson DW and Hayden MR (2002) Caspase 
cleavage of mutant huntingtin precedes neurodegeneration in Huntington's disease. J. Neurosci. 22: 7862-7872

32. Gafni J and Ellerby LM (2002) Calpain activation in Huntington's disease. J. Neurosci. 22: 4842-4849

33. Zuccato C, Ciammola A, Rigamonti D, Leavitt BR, Goffredo D, Conti L, MacDonald ME, Friedlander RM, Silani V, Hayden MR, Timmusk T, Sipione S and Cattaneo $E$ (2001) Loss of huntingtin-mediated BDNF gene transcription in Huntington's disease. Science 293: 493-498

34. Hackam AS, Singaraja R, Wellington CL, Metzler M, McCutcheon K, Zhang T, Kalchman M and Hayden MR (1998) The influence of huntingtin protein size on nuclear localization and cellular toxicity. J. Cell Biol. 141: 1097-1105

35. Martindale D, Hackam A, Wieczorek A, Ellerby L, Wellington C, McCutcheon K, Singaraja R, Kazemi-Esfarjani P, Devon R, Kim SU, Bredesen DE, Tufaro F and Hayden MR (1998) Length of huntingtin and its polyglutamine tract influences localization and frequency of intracellular aggregates. Nat. Genet. 18: $150-154$

36. Wellington CL, Singaraja R, Ellerby L, Savill J, Roy S, Leavitt B, Cattaneo E, Hackam A, Sharp A, Thornberry N, Nicholson DW, Bredesen DE and Hayden MR (2000) Inhibiting caspase cleavage of huntingtin reduces toxicity and aggregate formation in neuronal and nonneuronal cells. J. Biol. Chem. 275: 19831-19838

37. Troy CM, Rabacchi SA, Hohl JB, Angelastro JM, Greene LA and Shelanski ML (2001) Death in the balance: alternative participation of the caspase-2 and -9 pathways in neuronal death induced by nerve growth factor deprivation. J. Neurosci. 21: 5007-5016

38. Sanchez I, Xu CJ, Juo P, Kakizaka A, Blenis J and Yuan J (1999) Caspase-8 is required for cell death induced by expanded polyglutamine repeats. Neuron. 22: 623-633

39. Krajewski S, Krajewska M, Ellerby LM, Welsh K, Xie Z, Deveraux QL, Salvesen GS, Bredesen DE, Rosenthal RE, Fiskum G and Reed JC (1999) Release of caspase-9 from mitochondria during neuronal apoptosis and cerebral ischemia. Proc. Natl. Acad. Sci. USA 96: 5752-5757

40. Mancini M, Machamer CE, Roy S, Nicholson DW, Thornberry NA, CasciolaRosen LA and Rosen A (2000) Caspase-2 is localized at the Golgi complex and cleaves golgin-160 during apoptosis. J. Cell Biol. 149: 603-612

41. Rao RV, Peel A, Logvinova A, del Rio G, Hermel E, Yokota T, Goldsmith PC, Ellerby LM, Ellerby HM and Bredesen DE (2002) Coupling endoplasmic reticulum stress to the cell death program: role of the ER chaperone GRP78. FEBS Lett. 514: 122-128

42. Yaoita $Y(2002)$ Inhibition of nuclear transport of caspase-7 by its prodomain. Biochem. Biophys. Res. Commun. 291: 79-84

43. Miyashita T, Matsui J, Ohtsuka Y, Mami U, Fujishima S, Okamura-Oho Y, Inoue T and Yamada M (1999) Expression of extended polyglutamine sequentially activates initiator and effector caspases. Biochem. Biophys. Res. Commun. 257: 724-730

44. Li H, Li SH, Johnston H, Shelbourne PF and Li XJ (2000) Amino-terminal fragments of mutant huntingtin show selective accumulation in striatal neurons and synaptic toxicity. Nat. Genet. 25: 385-389

45. Slow EJ, Van Raamsdonk J, Rogers D, Coleman SH, Graham RK, Deng Y, Oh R, Bissada N, Hossain SM, Yang YZ, Li XJ, Simpson EM, Gutekunst CA, Leavitt BR and Hayden MR (2003) Selective striatal neuronal loss in a YAC128 mouse model of Huntington disease. Hum. Mol. Genet. 12: $1555-1567$

46. Mende-Mueller LM, Toneff T, Hwang SR, Chesselet MF and Hook VY (2001) Tissue-specific proteolysis of Huntingtin (htt) in human brain: evidence of enhanced levels of $\mathrm{N}$ - and $\mathrm{C}$-terminal htt fragments in Huntington's disease striatum. J. Neurosci. 21: 1830-1837

47. Saudou F, Finkbeiner S, Devys D and Greenberg ME (1998) Huntingtin acts in the nucleus to induce apoptosis but death does not correlate with the formation of intranuclear inclusions. Cell 95: 55-66 